\title{
Research Paper \\ The Effectiveness of the Five Senses Enhancement Training on Cognitive Ability and Social Skills of Students with Mathematical Learning Disabilities
}

\author{
Malakeh Sadat Sayedie ${ }^{1}$, Samaneh Sadat Tabatabaee ${ }^{* 2}$, Toktam Sadat Tabatabaee ${ }^{2}$, Fatemeh Shahabizadeh \\ 1. Ph.D Student of Educational Psychology, Birjand Branch, Islamic Azad University, Birjand, Iran \\ 2. Assistant Professor, Department of Psychology, Birjand Branch, Islamic Azad University, Birjand, Iran \\ 3. Associate Professor, Department of Psychology, Birjand Branch, Islamic Azad University, Birjand, Iran
}

Citation: Sayedie MS, Tabatabaee SS, Tabatabaee TS, Shahabizadeh F.

The effectiveness of the five senses enhancement training on cognitive ability and social skills of students with mathematical learning disabilities. J Child Ment Health. 2021; 8 (2):46-61.

URL: $\underline{\text { http://childmentalhealth.ir/article-1-1113-en.html }}$
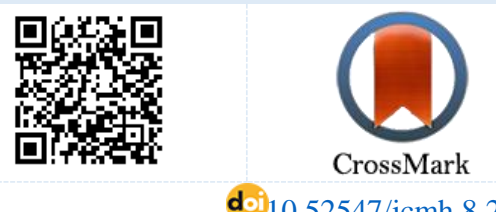

do $10.52547 / \mathrm{jcmh} .8 .2 .46$

(2) 20.1001.1.24233552.1400.8.2.7.8
Open

Access

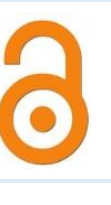

\section{A R T I C L E I N F O}

Keywords:
Five senses,
cognitive ability,
social skills,
learning disability

Received: 1 Mar 2021

Accepted: 24 May 2021

Available: 18 Sep 2021

\section{A B S T R A C T}

Background and Purpose: A specific learning disability is a disorder that interferes with a student's ability to listen, think, speak, write, spell, or do mathematical calculations. Students with a specific learning disability may struggle with reading, writing, or math. This study aimed to investigate the effectiveness of the five senses enhancement training (5-SET) on cognitive ability and social skills of students with mathematical learning disabilities (MLD).

Method: The present study was a quasi-experimental study with pretest-posttest-follow-up design with control group. The statistical population included all students referred to the Learning Problems Center of Ferdows City in the 2019-20 academic year. A sample of 30 students was selected by purposive sampling and randomly assigned in the control and experimental groups. Then, the Wechsler Intelligence Scale for Children (WISC-IV) (2003) was performed, and the Matson Evaluation of Social Skills with Youngsters (1983) and Behavior Rating Inventory of Executive Function (Givia et al., 2000) were used as data collection instruments in two phases of pretest and posttest. The experimental group received the 5-SET for ten 70-minutes-sessions, while the control group underwent no interventions. Then, both groups were assessed as the posttest. Finally, the follow-up phase was performed after two months. Data were analyzed by the one-way analysis of covariance in the SPSS statistics-23 software.

Results: The results of the data analysis showed that the effect of the group on the combination of cognitive ability variables $(\mathrm{F}=149.942, \mathrm{p}<0.001$, effect size $=0.847)$ and social skills $(\mathrm{F}=126.809$, $\mathrm{P}<0.001$, effect size $=0.824$ ) is significant in students with learning disabilites.

Conclusion: According to the results of the present study the 5-SET can be used as an effective intervention on the cognitive ability and social skills of students with MLD.

* Corresponding author: Samaneh Sadat Tabatabaee, Assistant Professor, Department of Psychology, Birjand Branch, Islamic Azad University, Birjand, Iran.

E-mail: Tabatabaee88@yahoo.com

Tel: (+98) 5632345571

2476-5740/ (C) 2021 The Authors. This is an open access article under the CC BY-NC-ND license

(https://creativecommons.org/licenses/by-nc-nd/4.0/). 


\section{Extended Abstract}

\section{Introduction}

Students with learning disabilities (LD) are generally of average or above-average intelligence, but they have poorer academic performance and more social problems compared to other students with the same educational status, and even with moderate intelligence they have difficulties in certain areas (reading, writing and, mathematics) (1). Math learning disabilities (MLD) influence on the children's talents and abilities and cause behavioral and psychological problems in them (3). The prevalence of MLD in schools is reported to be $4 \%$ to $7 \%$ (4).

Cognitive disability is one of the variables that can affect the academic performance of students with specific learning disabilities. The term executive action is also used to describe cognitive ability, which is closely related to children's academic achievement and success in math and social skills (11). Students with LD also have poor social skills compared to their normal peers (15). Social skills are learned behaviors that affect relationships between individuals and are acquired primarily through learning (18). Using intervention programs to strengthen cognitive processes (improving working memory, response inhibition, enhancing attention, and eliminating distraction) improves attention deficiency and hyperactive behaviors and indirectly affects social skills (19). A person's senses also affect his cognitive skills and abilities. In addition to the role of the senses of sight, hearing, and touch in learning, the sense of smell and taste play an important role in attention, concentration, and memory (21). Simultaneous use of aromatic stimulation with other traditional stimulation can improve students' perception, and performance, ability to remember and quality of experience (22). Research on the concepts of learning sciences, including mathematics, led to probing the cognitive benefits of multisensory methods (25). Distraction, poor response to stimuli, poor behavioral organization, and poor coordination between different senses can directly or indirectly affect social skills in children with LD (26). Numerous studies have shown the effectiveness of cognitive ability on improving mathematical performance $(13,14)$, the need to consider developing social skills $(15,17-19)$, and the importance of multisensory methods in learning and improving understanding and strengthening attention, concentration, and memory of students (20-24).

Based on the fact that no research has been done on the effect of five senses training on cognitive ability and social skills of students with LD, this study was conducted to determine the effectiveness of five senses training on cognitive ability and social skills of students MLD.

\section{Method}

The present study was a quasi-experimental study with the pretest-posttest-follow-up design with a control group. The population included students referred to the Learning Problems Center of Ferdows City, South Khorassan province, Iran in the 2019-20 academic year. A sample of 30 students was selected by the purposive sampling method. They were randomly assigned to the control and experimental groups. The the Wechsler Intelligence Scale for Children (WISC-IV) (27 \& 28) were used, and students with IQs less than 90 were excluded from the study sample. The ethical codes were also considered with the informed consent of the parents. They were assured of the confidentiality of the results. Data were collected by the Matson Evaluation of Social Skills with Youngsters (29) and Behavior Rating Inventory of Executive Function (30) in the pretest. It should be noted that the Iranian version of the questionnaires was used in this study. The experimental group received the five senses enhancement training (5-SET) for ten 70-minutes-sessions, while the control group underwent no interventions. Then, both groups were assessed at the posttest, and 2-month follow-up. Data were analyzed by the analysis of covariance (ANCOVA) in the SPSS-23 software.

\section{Results}

Table 1 shows descriptive statistics (mean and standard deviation, kurtosis, and skewness) of cognitive ability and social skills scores in the experimental and control groups in the pretest, posttest, and follow-up phases.

Table 1. Descriptive statistics of two groups scores in cognitive ability and social skills varibles $(\mathrm{n}=30)$

\begin{tabular}{|c|c|c|c|c|c|c|}
\hline Variable & Condition & Group & Mean & Standard deviation & Skewness & Kurtosis \\
\hline \multirow{6}{*}{ Cognitive ability } & \multirow{2}{*}{ Pretest } & Experimental & 99.22 & 17.99 & 1.756 & 2.663 \\
\hline & & Control & 104.98 & 7.65 & -0.271 & -0.324 \\
\hline & \multirow{2}{*}{ Posttest } & Experimental & 63.28 & 19.10 & 1.822 & 2.574 \\
\hline & & Control & 104.55 & 5.70 & 1.046 & 0.386 \\
\hline & \multirow{2}{*}{ Follow-up } & Experimental & 46.28 & 8.57 & 0.503 & -0.630 \\
\hline & & Control & 90.66 & 15.88 & -1.201 & 2.982 \\
\hline \multirow{6}{*}{ Social skills } & \multirow{2}{*}{ Pretest } & Experimental & 143.40 & 7.34 & 0.336 & -1.280 \\
\hline & & Control & 11.13 & 1.807 & 0.880 & 1.480 \\
\hline & \multirow{2}{*}{ Posttest } & Experimental & 104.88 & 9.54 & 0.91 & -0.166 \\
\hline & & Control & 141.90 & 6.81 & 0.436 & -0.221 \\
\hline & \multirow{2}{*}{ Follow-up } & Experimental & 126.59 & 6.09 & 0.578 & -0.891 \\
\hline & & Control & 142.13 & 6.99 & 0.534 & -0.601 \\
\hline
\end{tabular}




\section{Quarterly Journal of Child Mental Health}

Vol. 8, No. 2, Summer 2021

According to the results of table1, the mean scores of cognitive ability and social skills in the experimental and control groups in the posttest phase compared to the pretest phase have changed. The increasing of cognitive variables in the posttest confirms that the problems of cognitive ability and social skills of the experimental group are reduced and thus show that the cognitive ability and social skills are improved. The assumptions of repeated measure ANCOVA are confirmed, then this test can be used in this study.

According to the results, the effect of the group on the combination of cognitive ability variables $(\mathrm{F}=149.942$, $\mathrm{p}<0.001$, effect size $=0.847)$ and social skills $(\mathrm{F}=126.809$, $\mathrm{P}$ $<0.001$, effect size $=0.824$ ) is significant in students with LD. These results show that about $85 \%$ of the variation in cognitive ability and about $82 \%$ of the variation in social skills is related to the difference between the two groups due to the training and the interaction of the dependent variables. Thus, the intervention has a significant effect on increasing the cognitive ability and social skills of students with LD. Also, the effect of group in time on the combination of cognitive ability $(\mathrm{p}=$ $0.836, \mathrm{~F}=0.044)$ and social skills $(\mathrm{F}=0.7, \mathrm{p}=0.410)$ in students with LD is not significant and the effect of time is not significant on the composition of the social skills variable $(\mathrm{F}=$ 1.957, $\mathrm{p}=0.173$ ) but it is significant on the composition of the cognitive ability variable $(\mathrm{F}=19.508, \mathrm{p}=0.001)$.

\section{Conclusion}

The present study aimed to investigate the effect of the 5-SET on the cognitive ability and social skills of students with MLD. The results of ANCOVA showed that the 5-SET had a significant effect on the cognitive ability and social skills variables. The results of the present study are consistent with similar previous studies $(13,14,20,24)$. They suggest that cognitive ability improves students' performance and mathematical content understanding of the $\mathrm{LD}$. The results are also in line with the results of previous research (19-26) on improving social skills. Therefore, it is noticeable that the 5SET significantly has effects on the cognitive ability and social skills of students with MLD.

These results show that sensory interventions can improve cognitive ability. Visual, auditory, tactile, taste, and olfactory stimuli can help to improve memory, attention, planning, organization, and monitoring, which are components of cognitive ability. Also, the five senses training can increase socialized responses, and it relatively improves the communication with peers. It also reduces inappropriate social skills, aggression, and over self-esteem. Accordingly, the 5SET has also had a significant effect on social skills.

One of the limitations of this research was that the research sample group was 1st-grade students. The findings of this study can be generalized to the target population, but generalization of the results to other areas with different age groups must be made cautiously. We suggest that future researchers perform this intervention for children with different learning disabilities, especially preschool students, by controlling the influential factors of age and gender and perform it in more diverse age groups. There is a lack of educational and intervention programs in considering the five senses in Iran. Also, the Educational centers don't spend enough time on this purpose. Therefore, the use of intervention programs to enhance the five senses using a series of various educational tools and multisensory educational software and programs in LD centers and primary schools can be efficient to improve cognitive ability and social skills and facilitate learning mathematical concepts.

\section{Ethical Considerations}

Compliance with ethical guidelines: This research has been extracted from the doctoral dissertation of the first author in educational psychology, in the Islamic Azad University, Birjand Branch, and the research design code is 162363396 , with ethics IR. BIRJAND. REC. 1399.002. In this research, the ethical codes such as obtaining the informed consent of the participants and confidentiality were considered by the authors. Funding: The present study has conducted without any sponsoring from a specific organization.

Authors' contribution: This article is part of the first author's doctoral dissertation under the supervising and advising of the other authors.

Conflict of interest: There is no conflict of interest for the authors in this study.

Acknowledgments: The authors of the article consider it necessary to appreciate all participants in the research. 


\section{اثربخشى آموزش تقويت حواس ينج گانه بر توانمندى شناختى و مهارتهاى اجتماعى دانش آموزان با اختلال ياد كيرى رياضى}

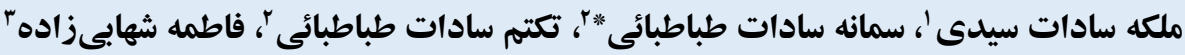

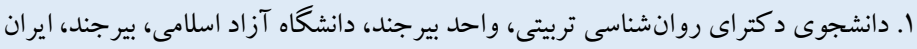

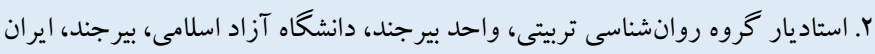

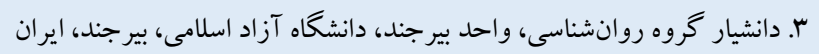

\section{?}

زمينه و هدف: كم توانى ياد گيرى خاص اختلالى اسـت كه با توانايى دانش آموز در گوش دادن، فكر كردن، صسحبت كردن، نوشــن، كر،

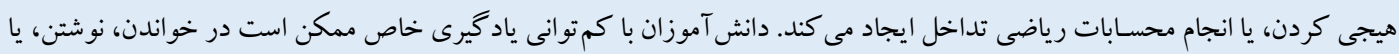

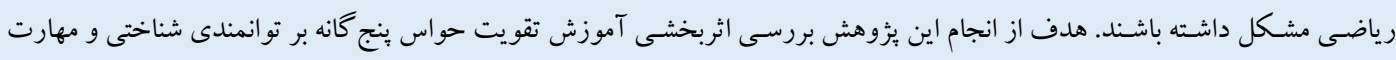
هاى اجتماعى دانش آموزان با اختلال يادگيرى رياضى بود.

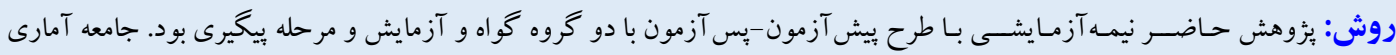

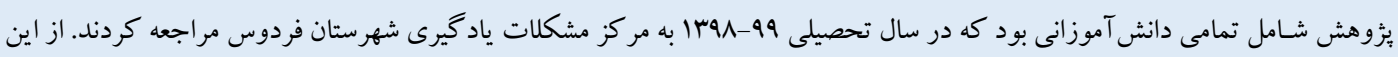

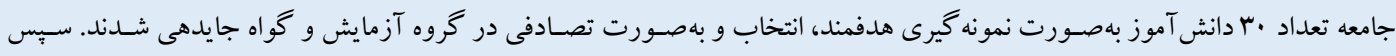

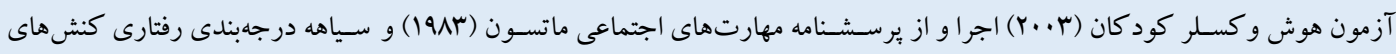

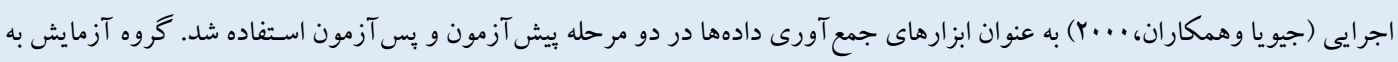

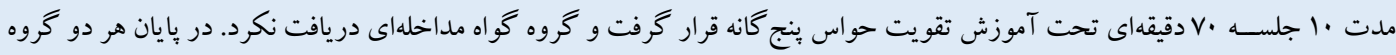

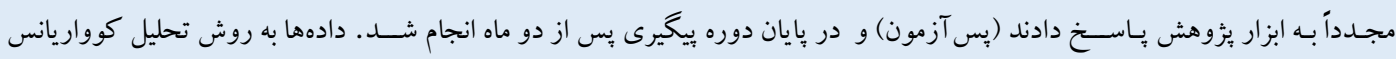
يكر اهه در محيط نرمافزار Spss نسخه سب تحليل شدند.

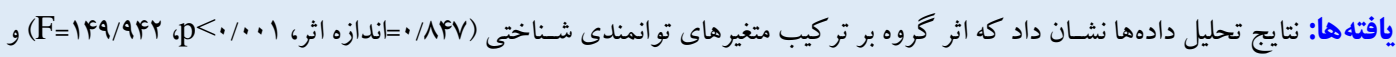

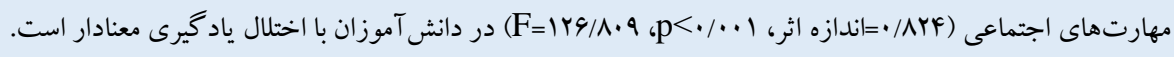
نتيجه كيرى: بر اسـاس يافتهاى اين يثزوهش، آموزش تقويت حواس ينج گانه مى تواند بهعنوان يكك مداخله مؤثر بر توانمندى شــناختى و

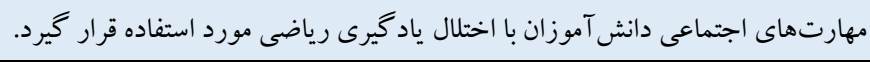

مشخصات مقاله

كليدوازههها: حواس بنج كانه،

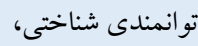
مهارت هاى اجتماعى، اختلال يادگيرى

دريافت شده: || |r/|

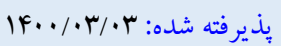

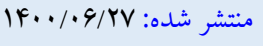

* نويسنده مسئول: سمانه سادات طباطبائى، استاديار گروه روانشناسى تربيتى، واحد بيرجند، دانشكاه آزاد اسلامى، بير جند، ايران. رايانامه: Tabatabaee88@yahoo.com 
اجرايى نقش مهمى در اختلـالـات يـاد گيرى دارد و دربر گيرنسده دامنـه

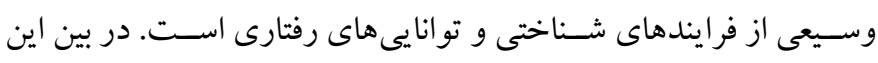

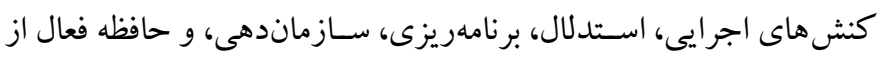

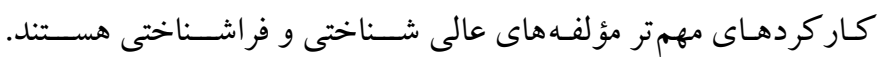

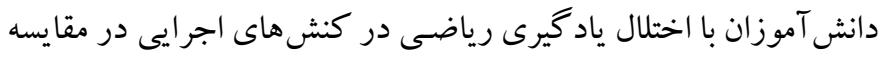
با كود كان با ساير اختلالات ياد گيرى، مشكلات بيشترى دارند و همجينين در حوزههاى سـازماندهى و برنامهريزى و بازدارى، مشكلات بيشترى را

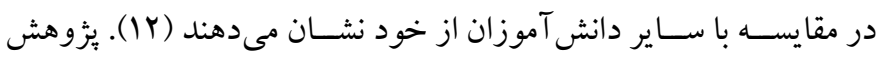

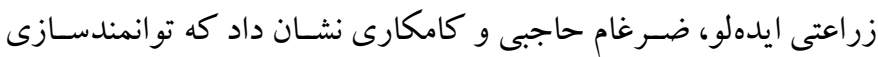

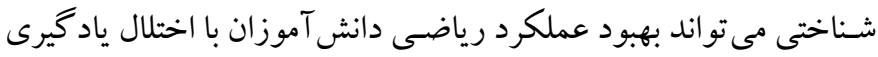

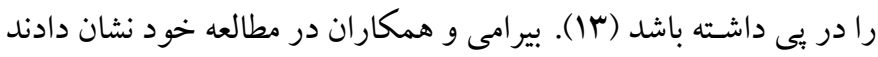

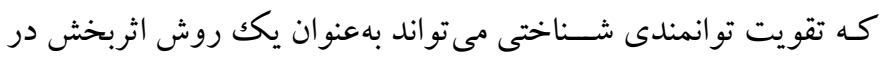
درمان اختلال ياد گيرى رياضى استفاده شود (1) (1). از سـوى ديخر، دانش آموزان با اختلال ياد گيرى در مقايسـه با سـاير دانش آموزان همســال خود در مهارتهاى اجتماعى نيز ضـعف دون دارند،

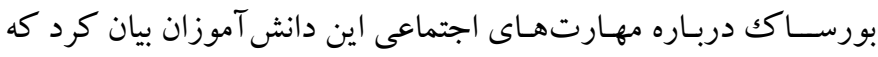
كود كان با اختلال ياد كيرى ممكن اسـت مشـكل اجتماعى بالاترى را در

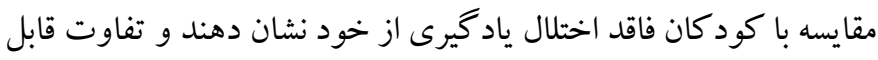

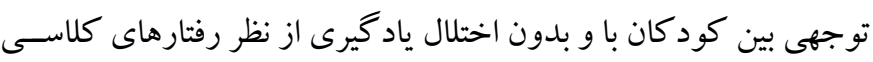

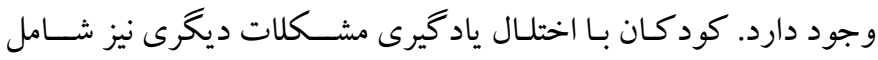

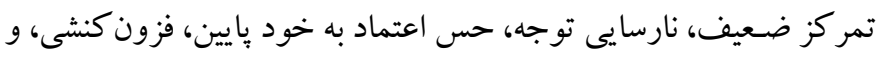

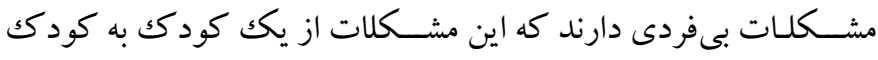

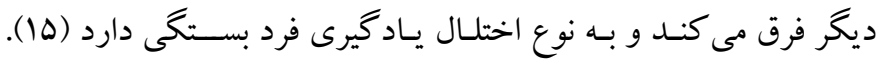

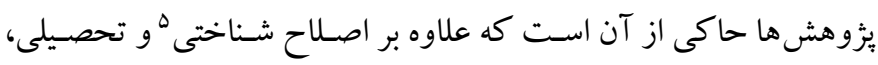

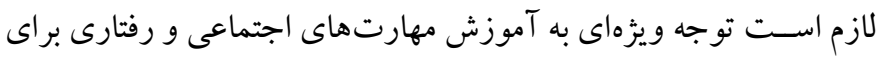

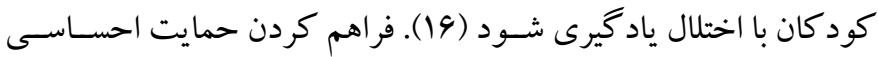

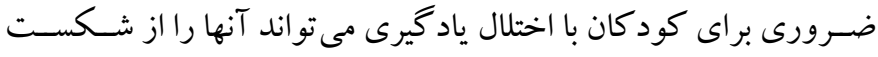

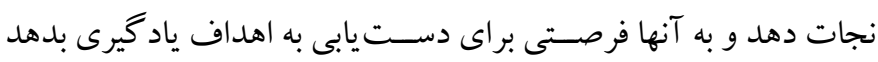
(IV)

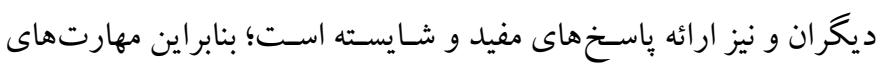

4. Social skills

5. Cognitive correction
مقدمه

بهطور معمول دانش آموزان با اختلال ياد كيرى'، از سطح هوشى متوسط

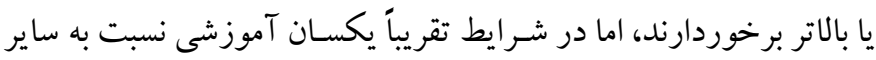

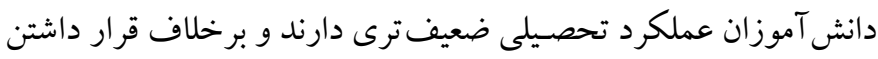
در محيط آموزشى مناسب و نيز نداشتن آسيبهاى عصبىزيستى آشكار

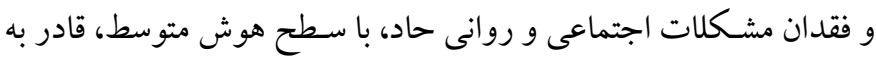
ياد گيرى در زمينه هاى خاصى (خواندن، نوشـتن و محاسبه) نيسـتند (1).

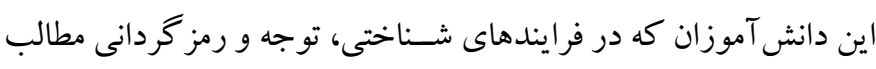
مشـكل دارند نسـبت به همتايان خود در تكاليف مربوط به حافظه فعال

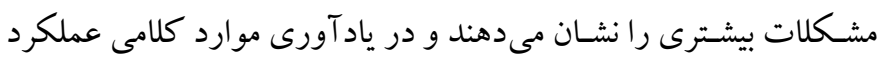

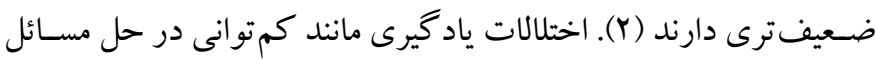

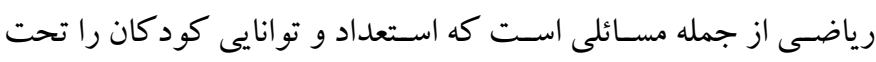

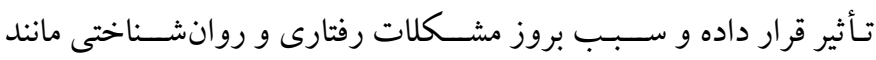

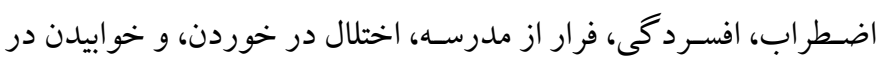

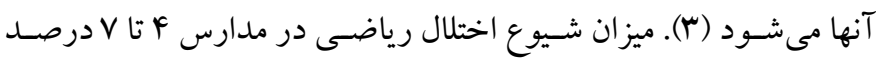

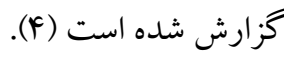

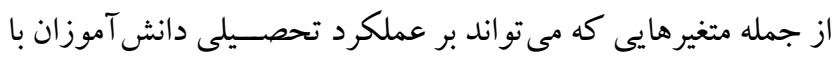

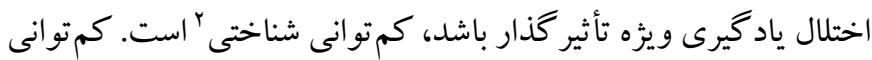

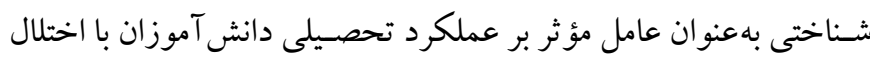

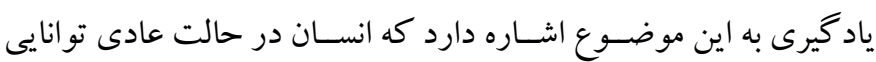

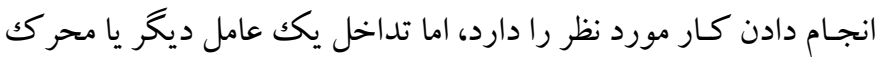
حو اسيرتى موجب مىشـود كه عملكرد فرد با بـدقتى همر اه باشـــ (ه).

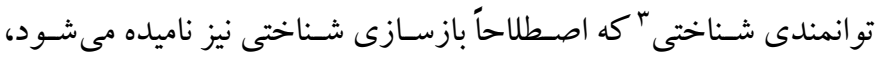

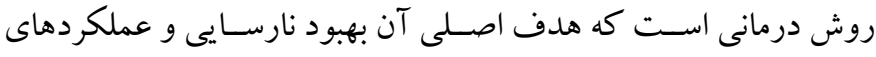

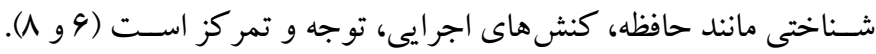
يزّوهش هايى كه با هدف افزايش توانمندسـازى دانش آموزان با اختلال

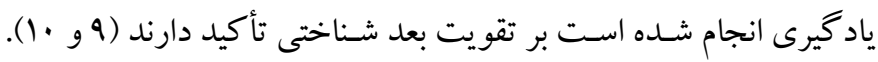

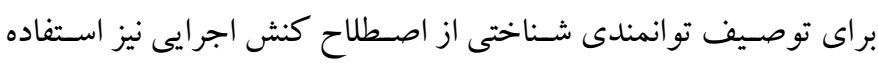

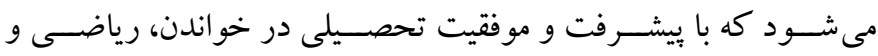

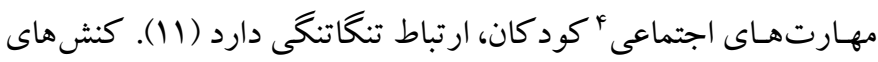

1. Learning disorders

2. Cognitive disability

3. Cognitive ability 
نكهـدارى اطلـاعـات فراهم مى كنــ (·Y). حواس فرد بر مهـارت هـا و

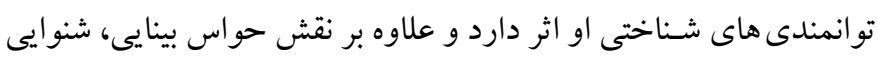

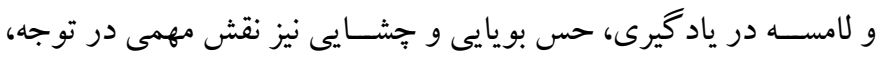

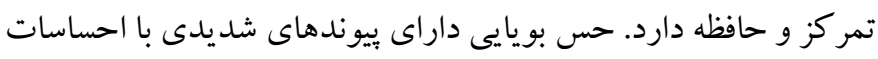

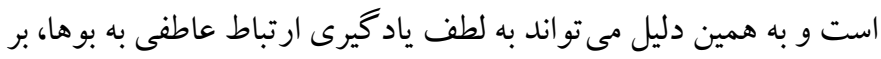

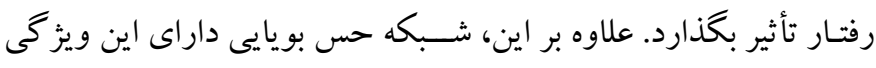

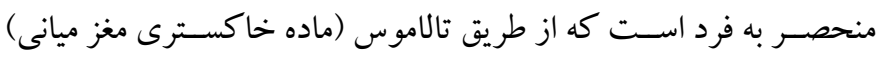

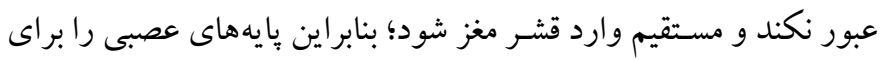

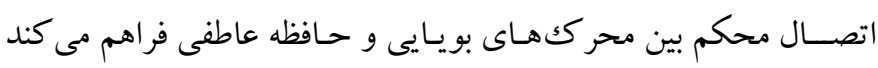

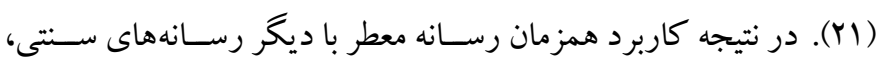

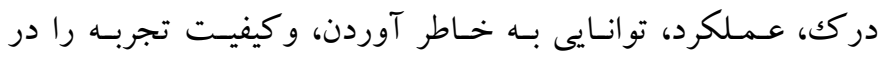
دانش آموزان بهبود مى دهــ (Yr). فعـاليت هايى كه همه حواس راس را دركير

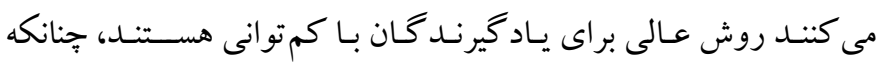

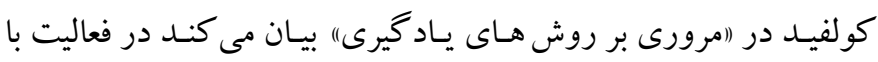

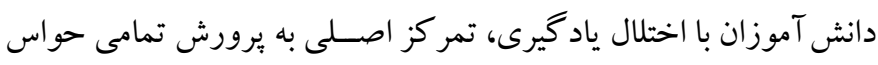

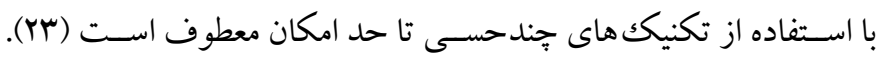
حس بو يايى در ادغـام بـا حواس ديخر نقش مهمى در ادراكى، حافظه، و

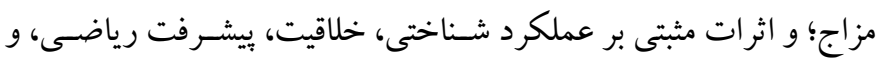
مهارت نوشـتن دارد و بهعنوان سازمان دهنده شناختى توصيف شده است

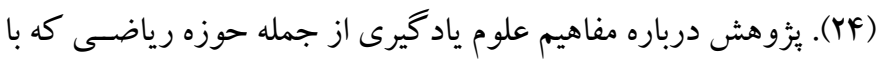

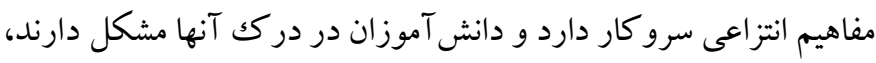

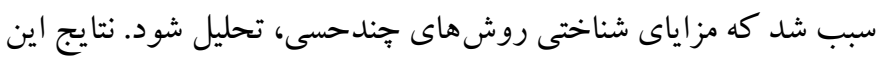

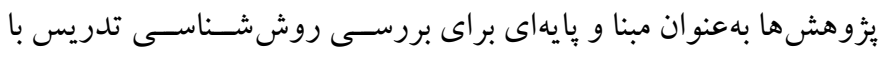

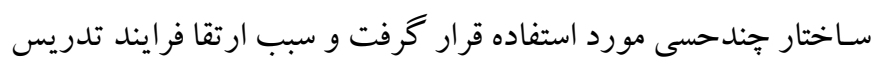

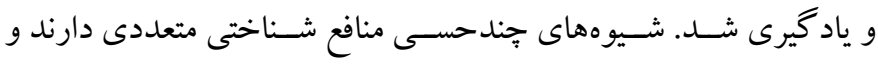

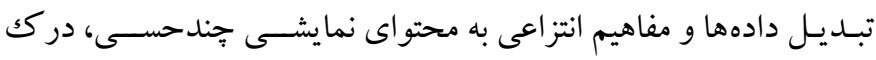

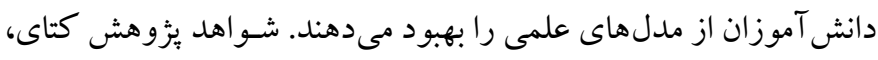

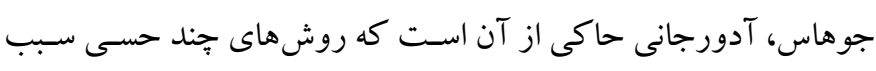

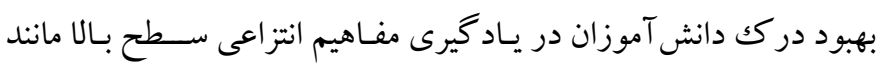

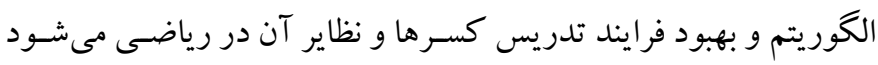

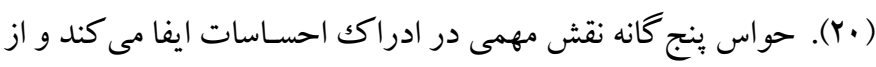

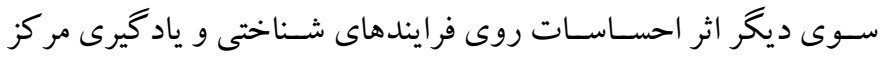

اجتمـاعى، رفتـارهـاى آموختنى هســند كه بر روابط ميان افراد تأثير مى

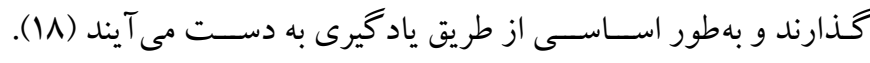

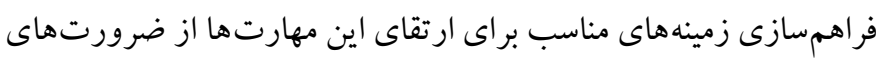

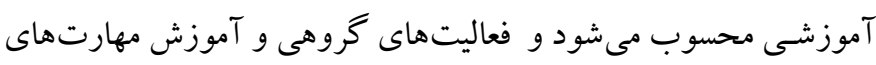

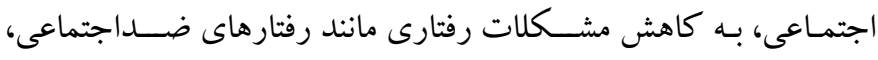

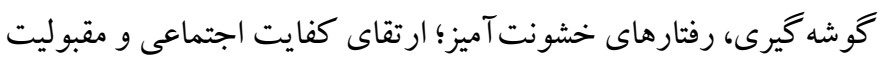

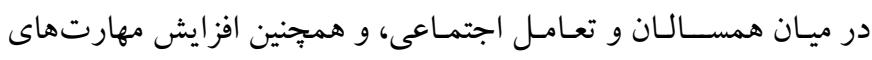

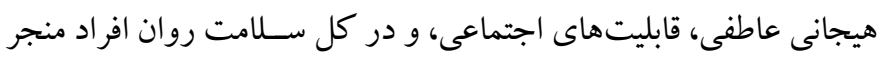

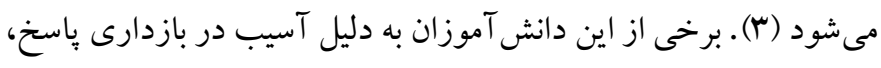

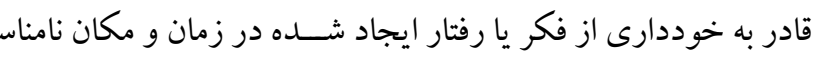

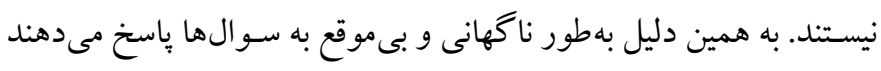

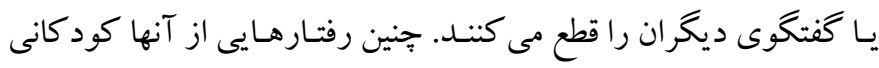
عجول نمايان مى كند و افزايش تنبيه، سرزنش، و طرد آنها را در بيى دارد.

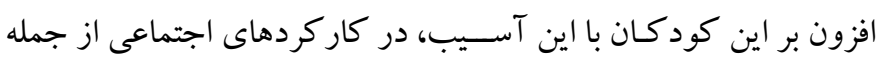

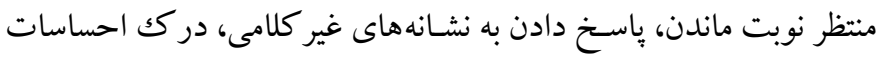

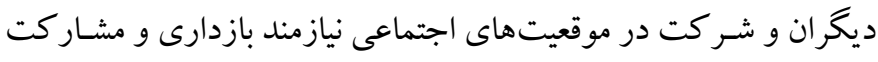

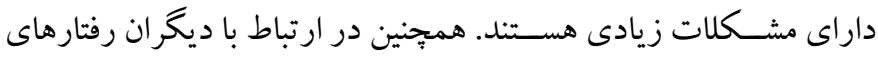

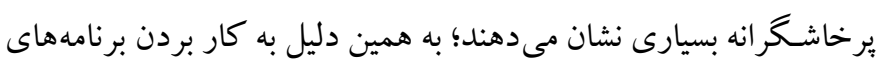

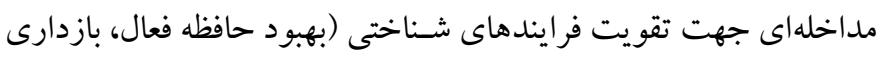

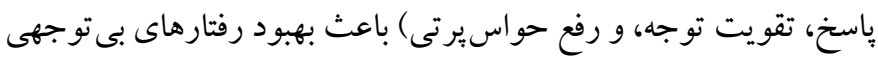

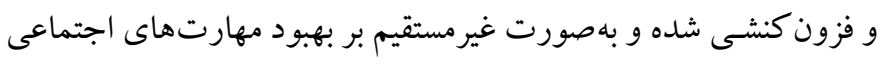

تأثير دارد (19). دريافت اطلاعات از مجراى حواس بنج گانه، امكان بازنمايى اطلاعات

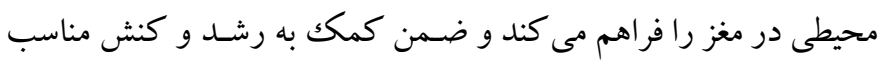

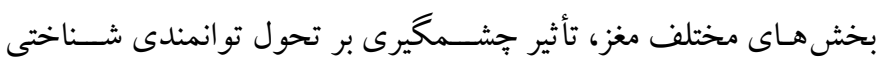

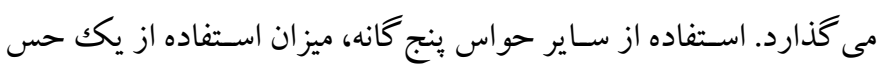
خاص، مهارتهاى حر كتى رشـديافته، جانبى شـدن نيمكرهها، آسيب در درد

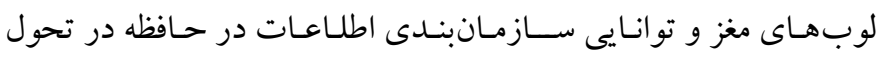

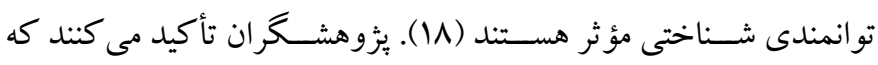
حواس نه فقط در احســاسـات، عواطف و حس زيبايىشـــاختى، كه در هر تفكر نيز نقش دارند و به كار گيرى حواس بيشتر به معناى كار آمدى بيشتر

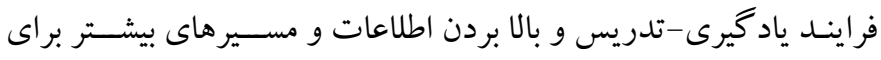




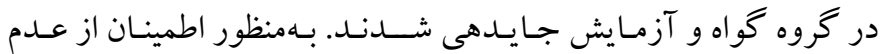
كم توانى ذهنى، از نمره هوشى آزمون و كسلر دانش آموزان استفاده شد و

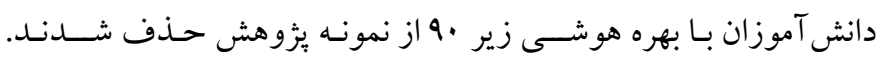

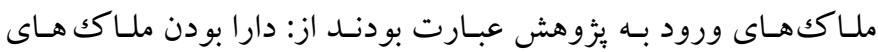

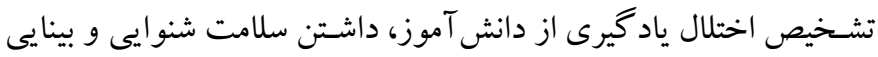
بر اسـاس طرح سـنجش، تحصيل در مدارس دولتى، برخوردارى از دامنه

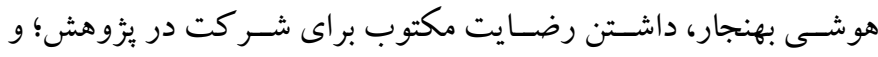

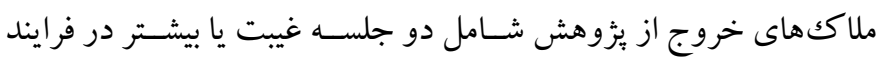

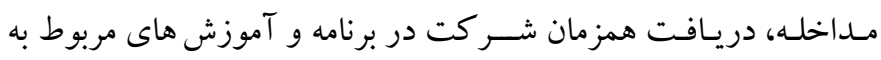

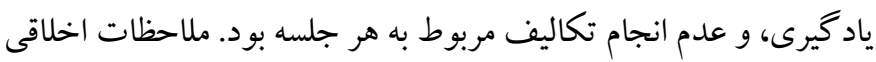

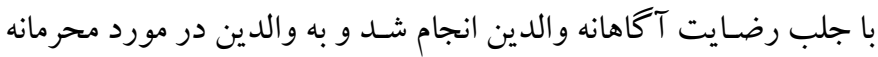

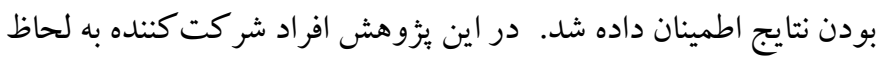

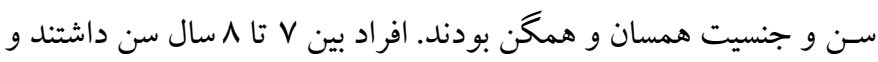

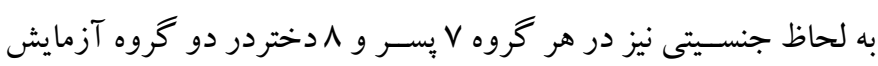

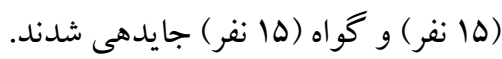

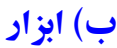
ا ـ آزمون هوش وكسلر (جهار) ': از اين آزمون براى وارسى ميزان هوش كود كان در اين مطالعه استفاده شده است. آزمون هوشى و كسلر يكى از

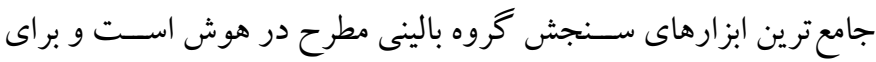

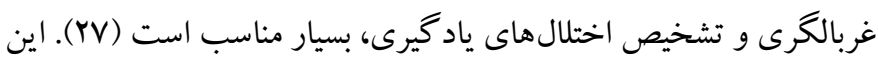

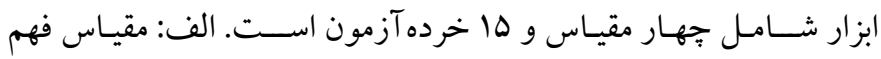
كلامى، ب: مقياس اسـتدلال ادراكك، ج: مقياس حافظه فعال، و د: مقياس

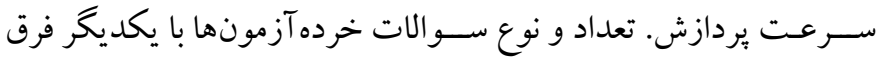

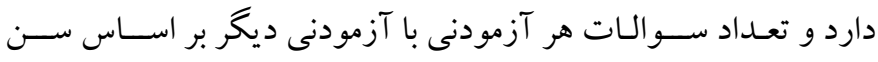

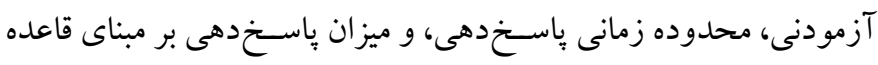

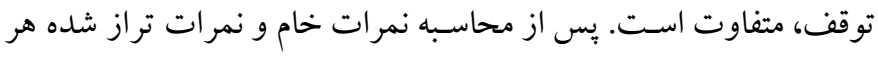

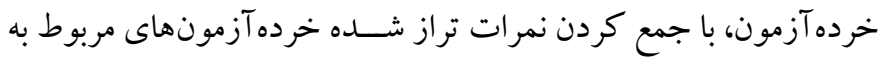

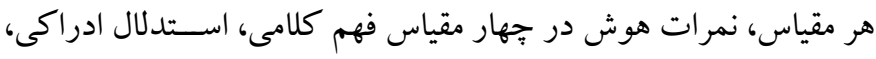

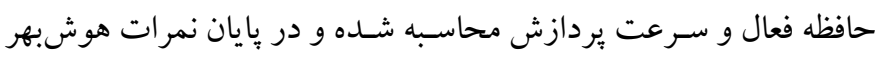

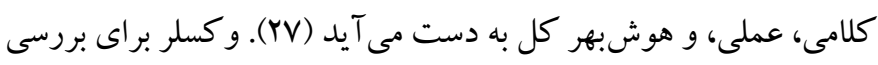

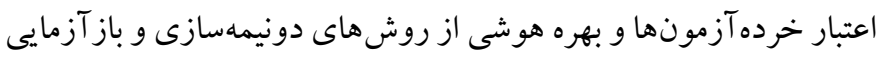

توجه بسـيارى از برزوهش هاى اخير اسـت. همجنين بر اسـاس مطالعات به

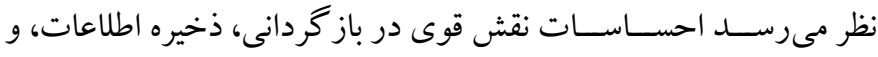

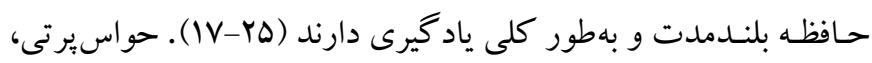

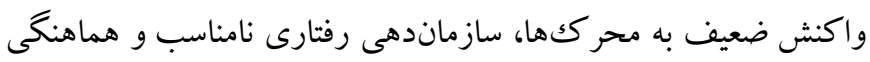
بايين بين حواس مختلف مىتواند بهطور مسـتقيم و يا غيرمسـتقيم مهارتهاى اجتماعى را در كود كان با اختلال يادگيرى تحت تأثير قرار مئرين

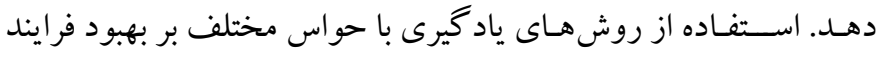

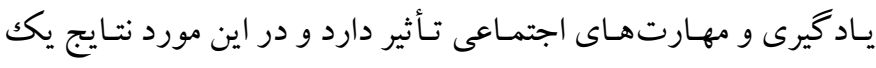
يزووهش نشان داد كه اثربخشى بازى با كلمات احساسى و تبديل فرايند

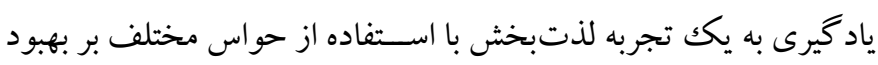

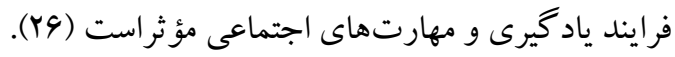
اكرجه در حوزه روش هاى جندحسى (ديدارى، شنيدارى، لامسه) در

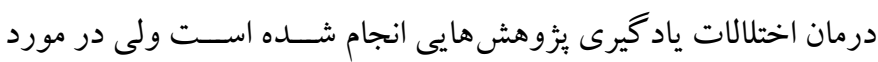

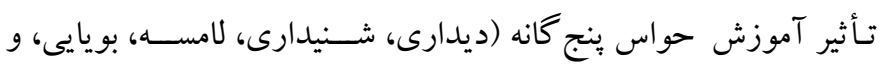

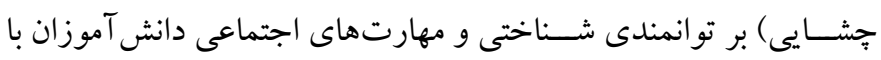

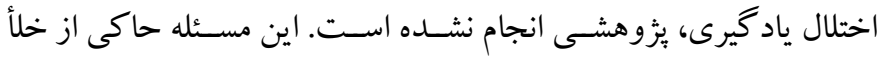

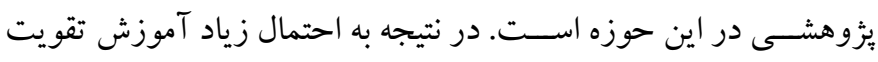

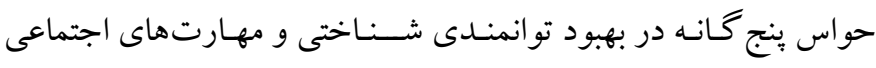

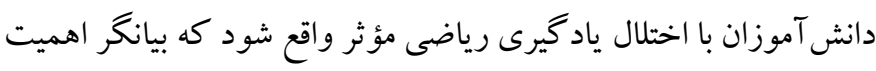

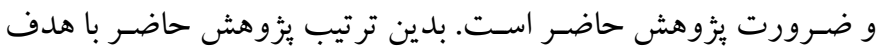

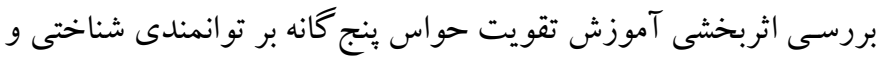

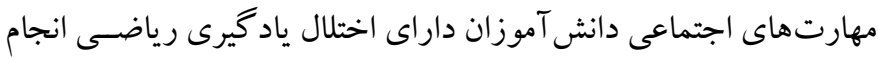
شد.

روش

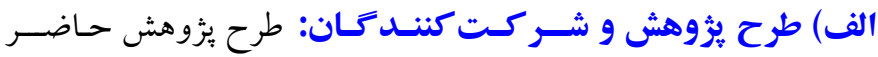

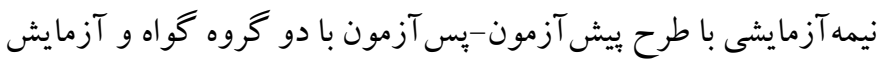

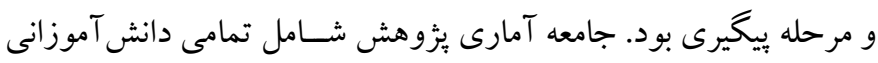

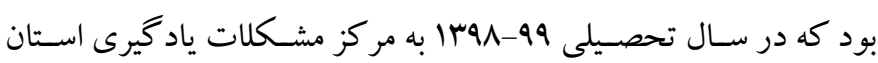

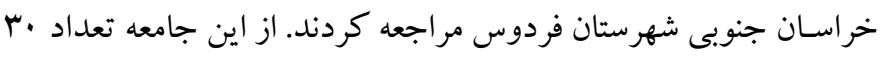

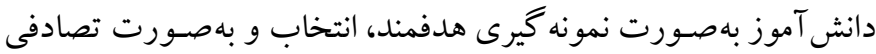


"م. برسشنامه كوتاه درجهبندى رفتارى كنش هاى اجرايى": اين برسشنامه

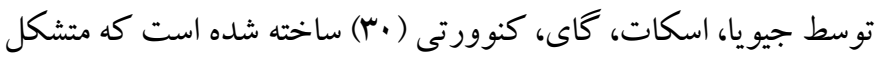

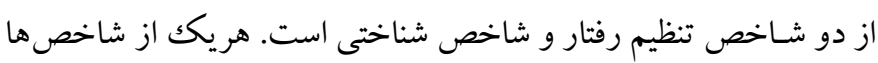

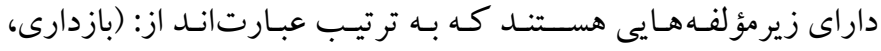

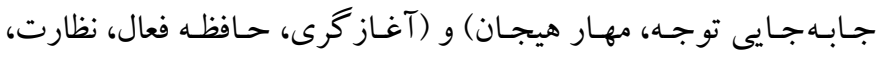

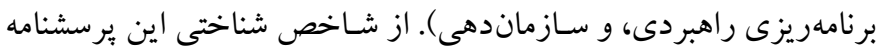

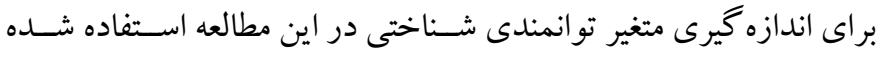

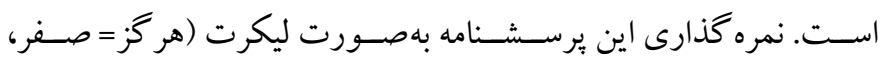
كاهى=يك و اغلب= دو) است ( اس) و كسب نمره بالا در اين ابزار، نشانه ضعف بيشتر در كنشهاى اجر ايى و مهارتهاى رفتارى است و در يايان

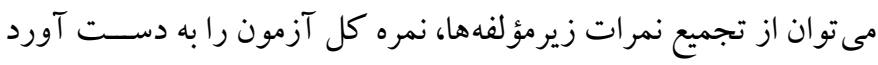

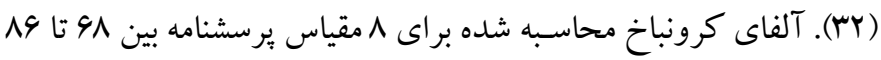

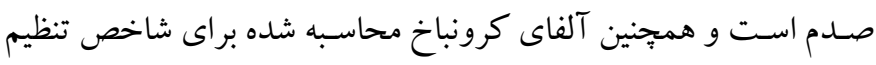

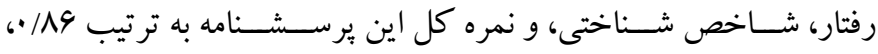

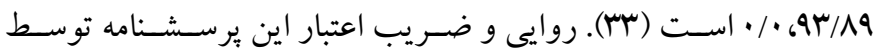

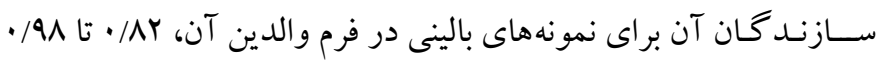

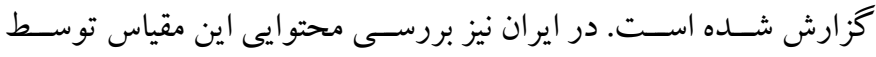
عبـدالمحمـدى، عليز اده، غديرى صــورمان آبادى، و طيبلى انجام و تأييد شـــ (Tr). براى خردهمقياس هاى تنظيم رفتارى و مهارت هاى فراشـناختى

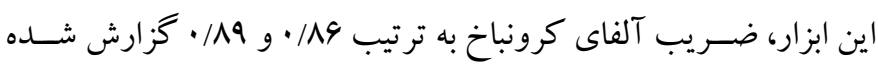

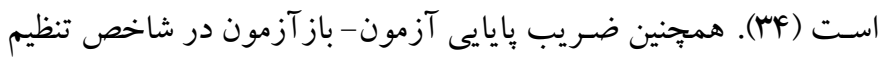

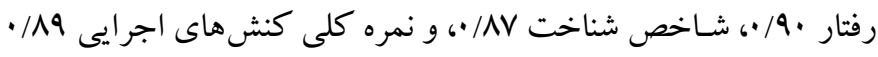

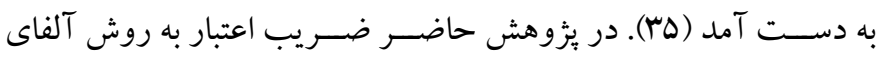

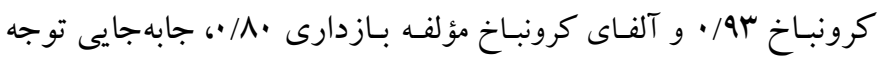

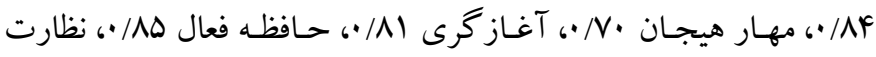

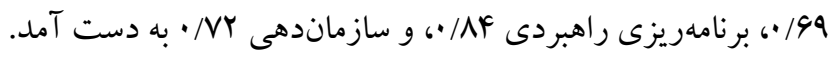
معرفى برنامه مداخلهاى: برنامه آموزشى بر اساس تلفيقى از روشهاى

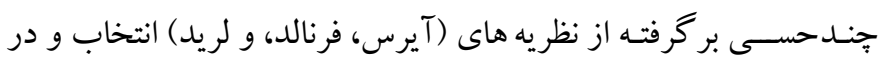

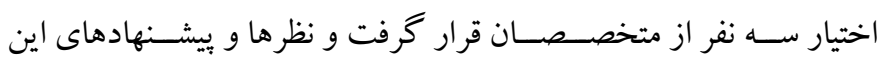
متخصـصــان در بسـته آموزشسى اعمال شـــــ روى آورد اين نظريه ها بر

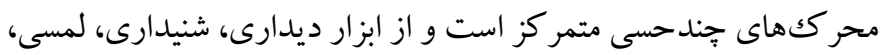

اسـتفاده كرده اسـت. ضـريب اعتبار بهره هوشى كلى 9V/ • گزارش شده

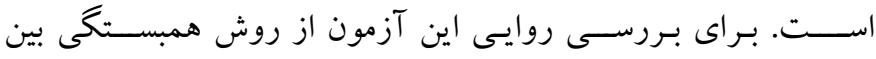

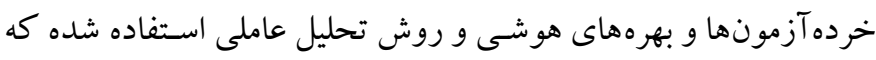
هر دو روش مؤيد روايى مناســبـ مقياس بوده اســت (YN). همجنين اين

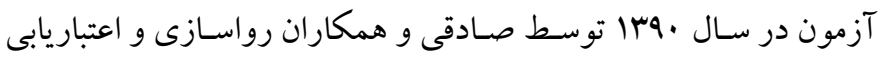
شد. اعتباريابى به روش باز آزمايى انجام شد كه ضريب اعتبار بهره هوشى ردى كلى (9)/ • گزارش شد (YN).

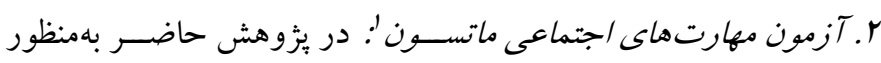

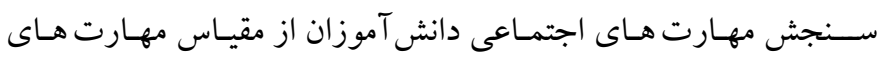

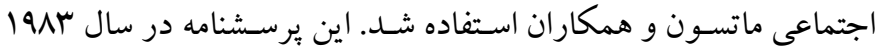
براى سـنجش مهارت هاى اجتماعى افراد F تا ل ا سـاله تدوين شده است.

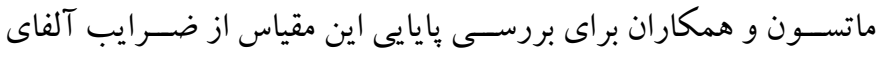

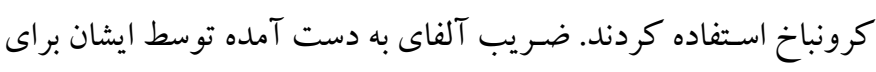

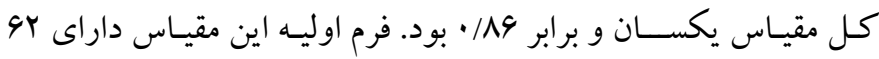

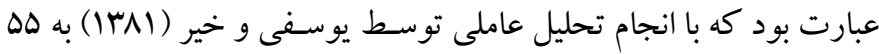
عبارت كاهش يافت كه مهارت هاى اجتماعى فرد را توصسيف مى كنند.

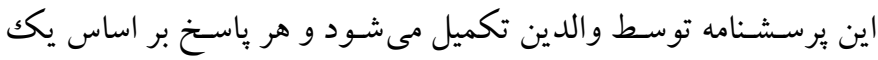

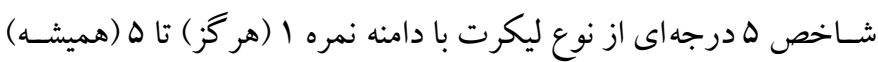
مشــخص مى شــود. براى اين مقيـاس هـ مقيـاس فرعى در قـالب هـ عامل

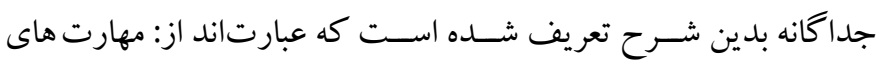

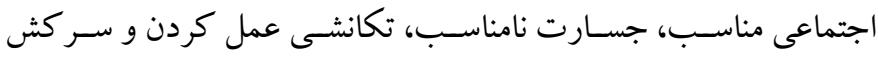

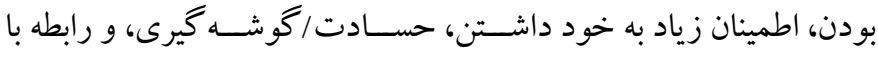

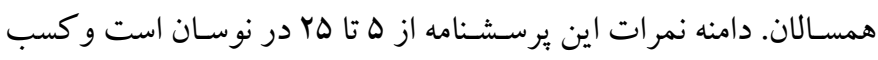

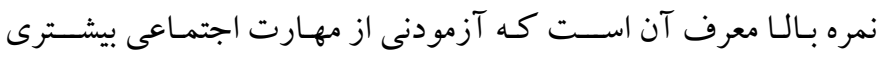
برخوردار استـ. اين مقياس توسط يوسـى و خير ترجمه و با استفاده از

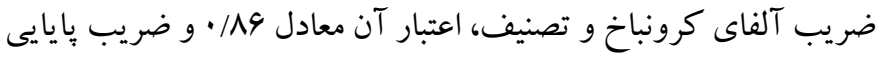

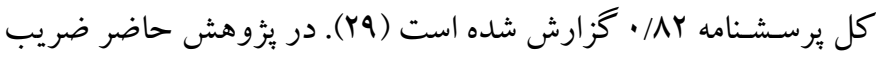

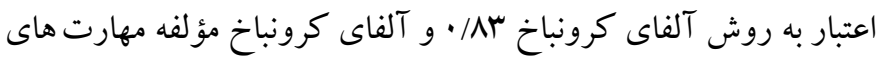

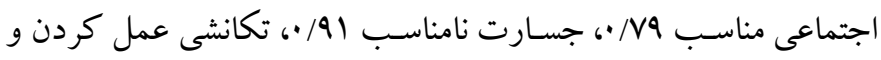

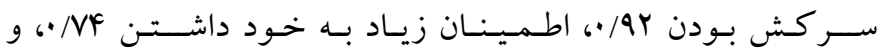

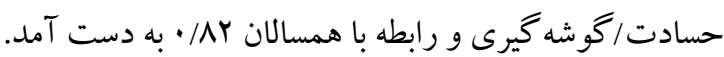


مادران در مركز مشكلات ياد گيرى شهرستان فردوس اجرا شد. در ابتداى

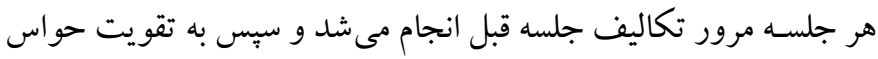

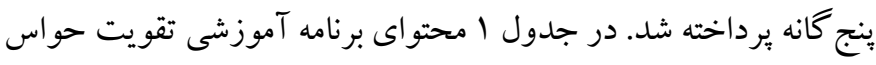
ينج گانه گزارش شده است.
جشـايى، و بويايى اسـتفاده مىشـود. بر اسـاس نظريههاى حسى تو انايى

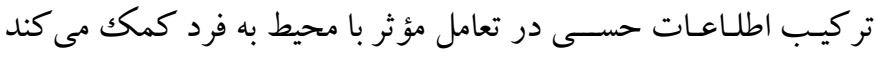

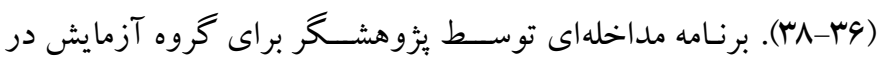

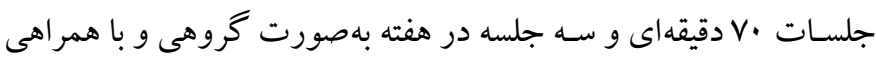

\section{جدول ا: محتواى برنامه آموزشى تقويت حواس بنج كانه}

\begin{tabular}{|c|c|c|}
\hline محتوا & اهداف & جلسات \\
\hline 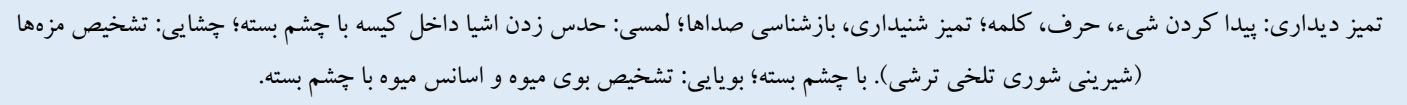 & تقويت حواس ينج كانه به & يكم \\
\hline 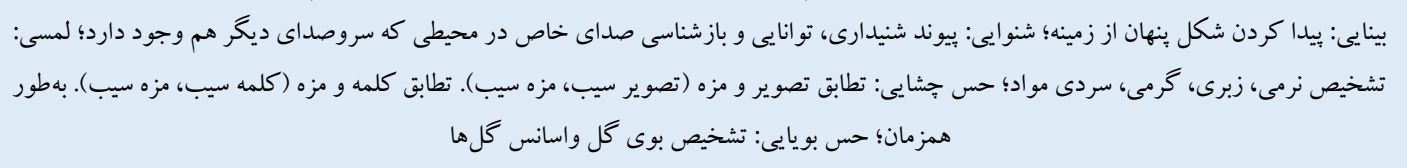 & مرور تكاليف قبلى، تقويت & دوم \\
\hline 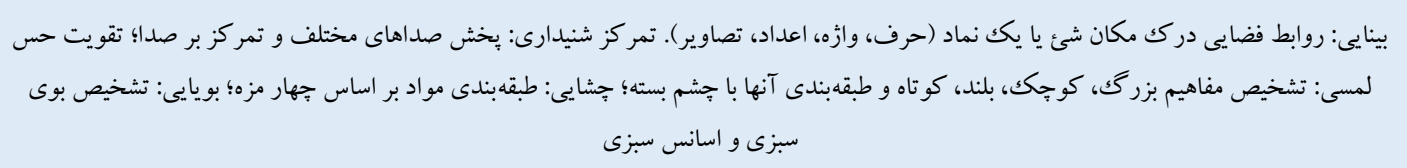 & مرور تماس بنج كانه به تفكيكى تقويت & سوم \\
\hline 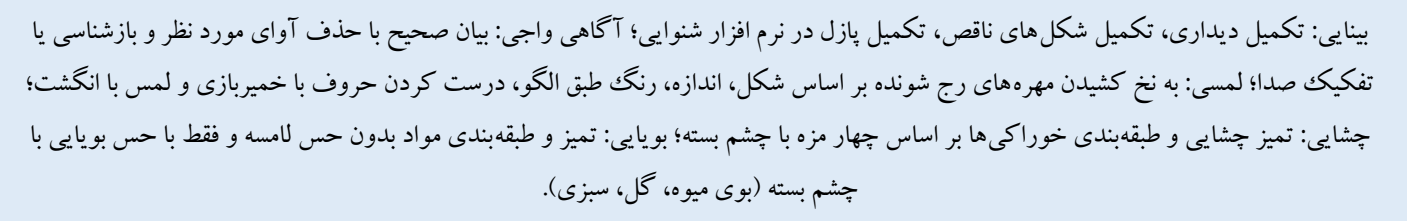 & 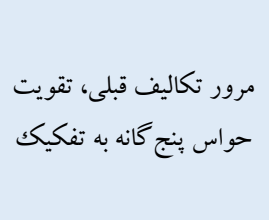 & جهارم \\
\hline 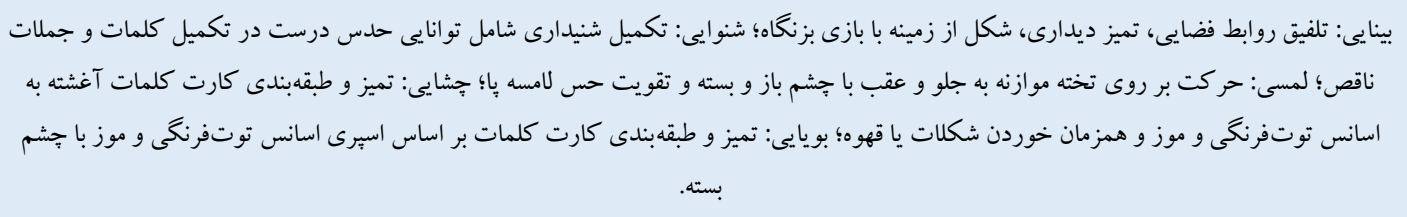 & 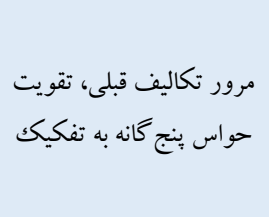 & يُنجم \\
\hline 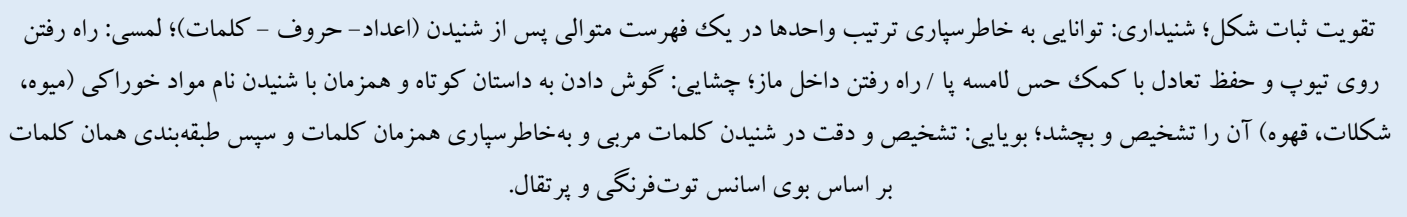 & 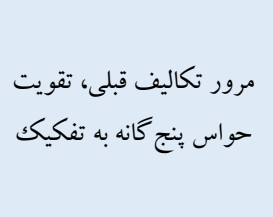 & ششم \\
\hline 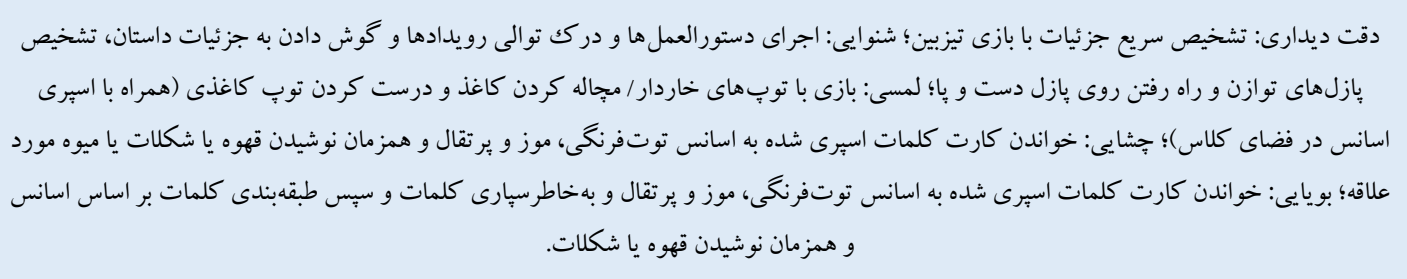 & مرور تكاليف قبلى، تلفيق & هفتم \\
\hline 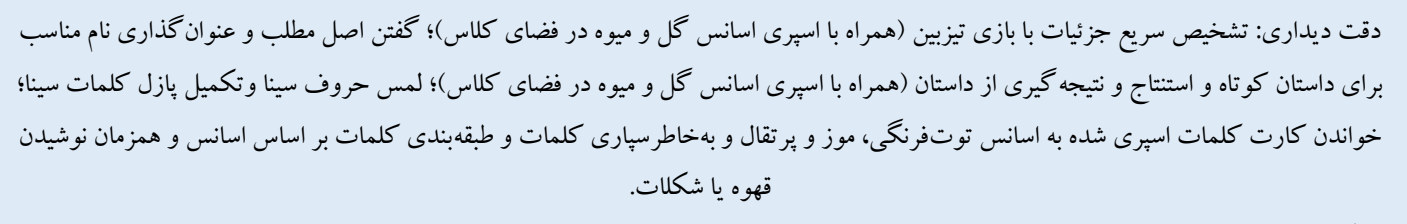 & مرور تكاليف قبلى، تلفيق & \\
\hline 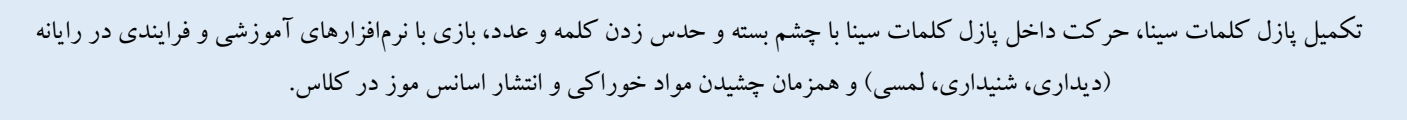 & مرور تكاليف قبلى، تلفيق & نهم \\
\hline 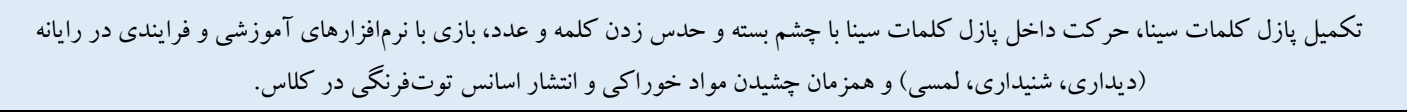 & مرور تكاليف قبلى، تلفيق & دهم \\
\hline
\end{tabular}


جلسـه •V دقيقهـ بـا همر اهى مادران دريافت كردند و گروه گواه در اين

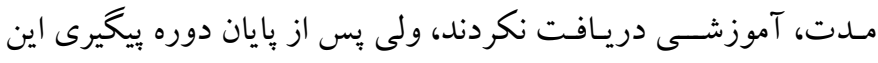

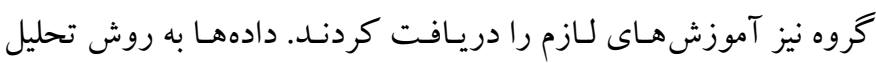
كوواريانس يكر اهه در محيط نرمافزار Spss نسخه بr تحليل شدند.

\section{يافته ها}

شــاخص هاى توصـيفى (ميانخين و انحر اف معيار، كشــيدگى و كجى)

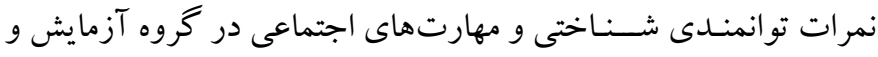

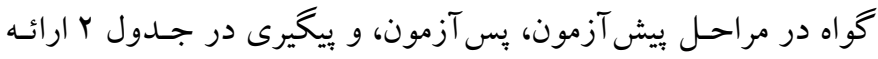

شده است.
روش اجرا: بِ از دريافت مصوبه اخلاق در يُزوهش و كسب مجوزهاى

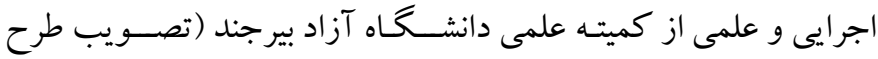

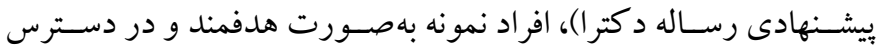
انتخاب شــند و در جلسـهاى اهميت و ضـرورت برسـشــامهها و تقويت

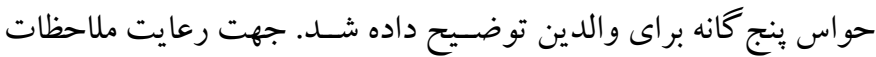

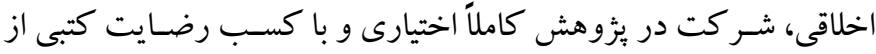

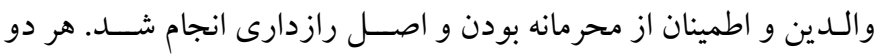

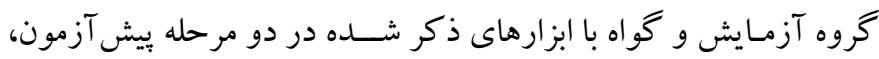

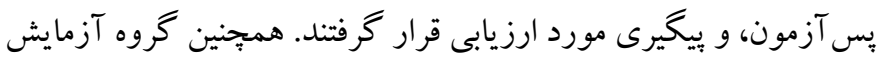

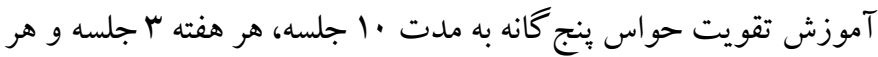

جدول r: شاخصهاى توصيفى نمرات آزمودنى هاى دو كروه در متغير توانمندى شناختى و مهارتهاى اجتماعى (تعداد •r نفر)

\begin{tabular}{|c|c|c|c|c|c|c|c|c|c|c|c|c|c|}
\hline \multicolumn{4}{|c|}{ ييغيرى } & \multicolumn{4}{|c|}{ ڤֶ آزمون } & \multicolumn{4}{|c|}{ بيش آزمون } & \multirow[b]{2}{*}{ متغير } & \multirow[b]{2}{*}{ كروه } \\
\hline كشيدكى & كجى & انحراف & ميانكين & كشيدكى & كجى & انحراف & ميانكين & كشيدكى & كجى & انحراف & ميانتين & & \\
\hline .194. & $\cdot / 0 \cdot r$ & $\Lambda / \Delta V$ & $F T / Y A$ & $r / \Delta V^{F}$ & I/AYY & $19 / 1$. & $9 \pi / Y \Lambda$ & $r / 994$ & I/VDG & $1 V / 99$ & $99 / Y Y$ & توانمندى & آزمايش \\
\hline r/QAY & $-1 / r \cdot 1$ & $10 / M$ & 9.194 & . / rAs & $1 / .49$ & $\Delta / v$ & $1 . \varphi / \Delta \Delta$ & $-\cdot /$ TYF & $-\cdot / Y V I$ & $V / 90$ & $1.4 / 91$ & شناختى & كواه \\
\hline$-\cdot / \wedge 9 \mid$ & $\cdot / \Delta \mathrm{VA}$ & 91.9 & $1 r 9 / \Delta 9$ & $-1 / 1 \Delta r$ & $-\cdot / \cdot \cdot V$ & N/99 & $|r N / F|$ & $-1 / Y \Lambda$. & 年 & $V / H F$ & $\mid k T / F$. & مهارتهاى & آزمايش \\
\hline$-\cdot / 9 \cdot 1$ & . /DHF & $9 / 99$ & $|F Y /| r$ & - $/ Y Y I$ &.$/ 4 r q$ & G|A| & $|f| / q$. &.$- / 194$ &.$/ .91$ & $q / \Delta F$ & $1 . F / M$ & اجتماعى & كواه \\
\hline
\end{tabular}

دامنه تغييرات شـاخص هاى كجى و كشيدگى در فاصـله (r، Y-)، توزيع دادهها نرمال اسـت. براى بررسـى همخنى واريانس با اسـتفاده از آزمون

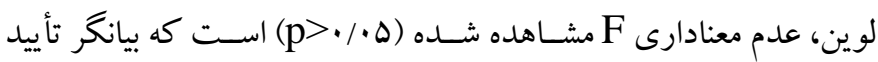
همســانى واريـانسها اســت. همســانى ماتريس كوواريانس ها از طريق

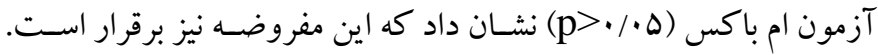

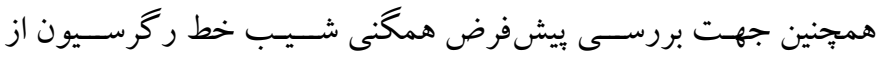

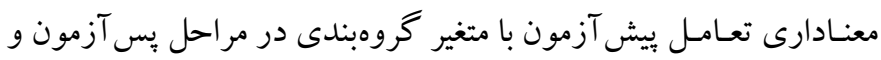

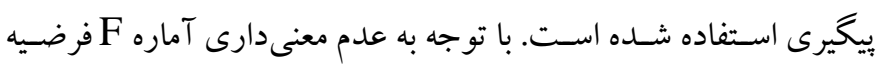

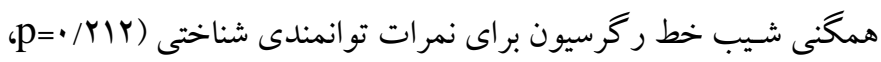

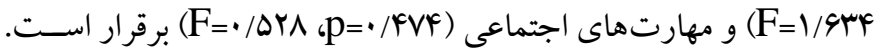

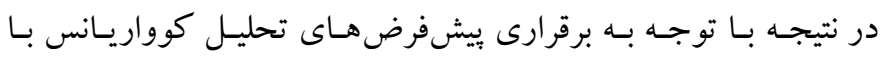

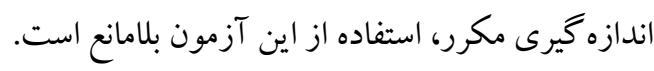

با توجه به جدول Y ميانگين نمرات تو انمندى شــناختى و مهارتهاى

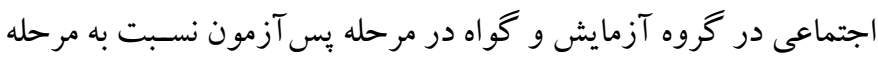
بيش آزمون تغيير اتى داشـته اسـت. كاهش متغير شــناختى در بس آزمون مؤيد آن اسـت كه مشـكلات تو انمندى شــاختى و مهارت هاى اجتماعى دئى

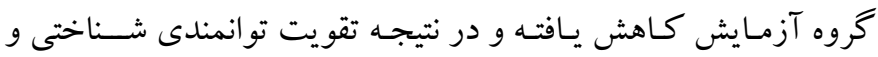
مهارت هاى اجتماعى را نشان مى دهد. فرضسيه يزوهش با استفاده از روش تحليل كوواريانس با اندازه گيرى

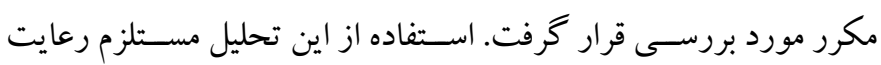
ييشفرض هايى است كه بيش از اجراى آزمون مورد بررسى قرار گرفت.

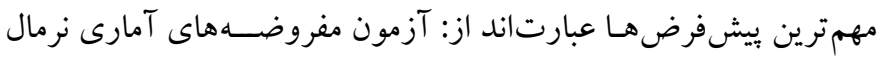

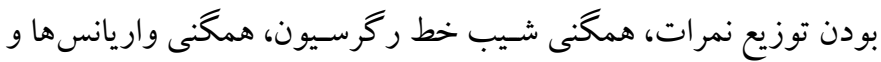

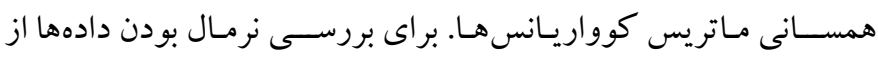

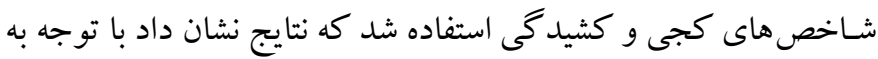


جدول r: نتايج تحليل كوواريانس با اندازه گيرى مكرر كروههاى آزمايش و كواه در مراحل ثئوهش

\begin{tabular}{|c|c|c|c|c|c|c|c|}
\hline اندازه اثر & معنادارى & Tاره F Tl & ميانكين مجذورات & درجه آزادى & مجموع مجذورات & منبع & متغيرها \\
\hline$\cdot / 419$ & $<\cdot / \cdot \cdot 1$ & $19 / 0 \cdot 1$ & . TAN & 1 & . & مراحل & \\
\hline - /AFV & $<\cdot / \cdot \cdot 1$ & IFq/qFY & $r / \Lambda \cdot r$ & 1 & $r / A \cdot r$ & كروه & تو انمندى شناختى \\
\hline$\% r$ & . /ArG &.$/ F F$ & $\cdot \cdots 1$ & 1 &.$/ \cdot 1$ & مراحل ** گروه & \\
\hline .1 .91 &.$/ 1 n$ & $1 / 9 \Delta V$ & $\cdot / \cdots q$ & 1 & $\cdot / \cdot 9$ & مر احل & \\
\hline - IAYF & $<\cdot / \cdot \cdot 1$ & $1 Y 9 / A \cdot 9$ & $1 / r 9 V$ & 1 & $1 / Y q V$ & كروه & مهارتهاى اجتماعى \\
\hline.$/$ ro &.$/ 41$ & $\cdot / \mathrm{r} \cdot$ & $\% r$ & 1 & . .r & مراحل ش* گروه & \\
\hline
\end{tabular}

آزمون بونفرونى نيز جهت بررسى بايدارى تقويت حواس بنج گانه بر

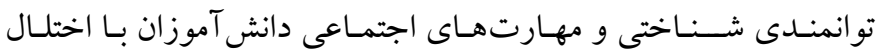

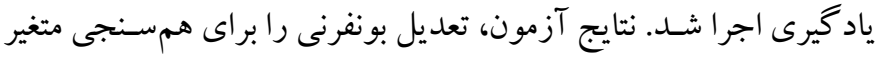

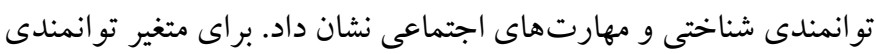

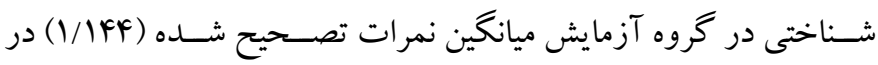

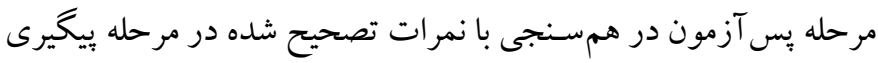

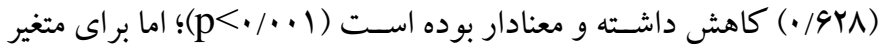
مهارتهـاى اجتمـاعى گروه آزمايش، ميانگين نمرات تصـحيح شـــده (Y/DQV)

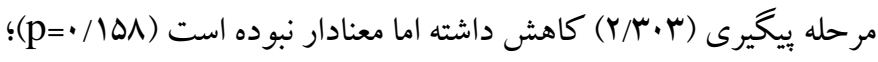
بنابر اين فرضــيه ثبات نتايج مداخله براى متغير توانمندى شــناختى تأييد نمى شود، ولى براى متغير مهارتهاى اجتماعى تأييد مى بود. در بررسى خردممؤلفه هاى متغيرهاى توانمندى شناختى و مهارت

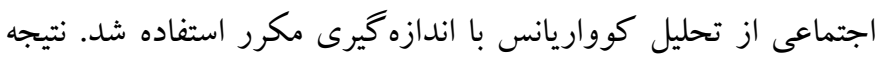
نهايى بِ از بررسى و تحليل در جدول \& ارائه شده است.
نتايج جدول Y نشان مى دهد، اثر گروه بر تر كيب متغيرهاى تو انمندى

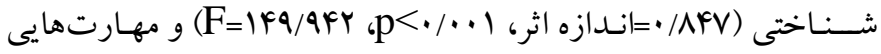

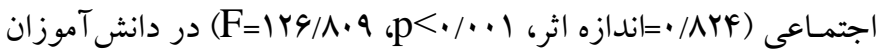

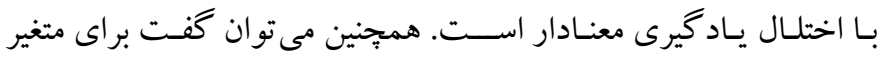

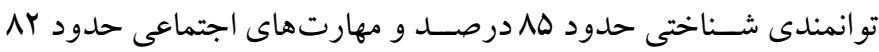

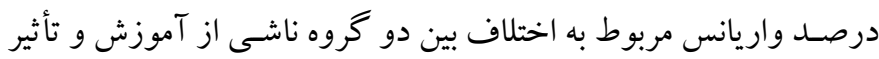
متقابل متغير وابسـته اســت. بدين ترتيب مداخله انجام شـــه بر افزايش

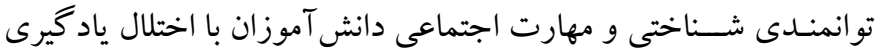

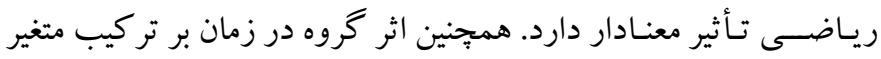

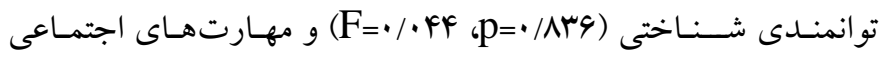

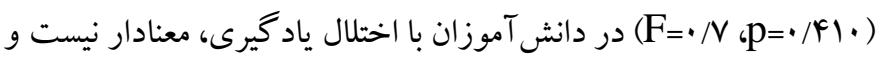

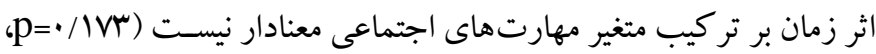

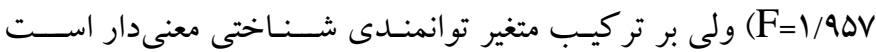

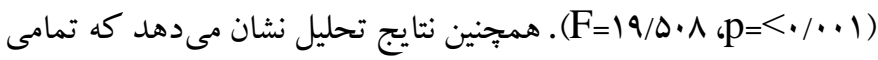

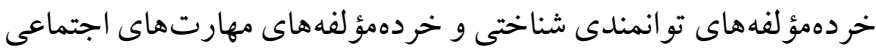

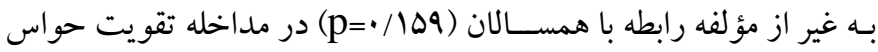

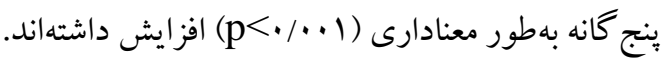


جدول ع: نتايج تحليل كوواريانس با اندازهكيرى مكرر براى مؤلفههاى توانمندى شناختى و مهارتهاى اجتماعى مدات

\begin{tabular}{|c|c|c|c|c|c|c|c|}
\hline اندازه اثر & معنادارى & Tاره Fاره & ميانكين مربعات & درجه آزادى & مجموع مربعات & خردهمؤلفه & مؤلفه \\
\hline . /V9 & $<\cdot / \cdot \cdot 1$ & $M N / 1$ & r/MG & 1 & $r / \mu^{\prime}$ & آغازگرى & \\
\hline$\cdot / \wedge$. & $<\cdot / \cdot \cdot 1$ & $1 . F / . * 1$ & F/YMF & 1 & $F / M$ & حافظه كارى & \\
\hline$\cdot / \Lambda$. & $<\cdot / \cdot \cdot 1$ & $11 \cdot / 49$ & $f / \Delta \Delta$ & 1 & $F / \Delta \Delta$ & برنامهريزى راهبردى & توانمندى شناختى \\
\hline$\cdot / N 1$ & $<\cdot / \cdot \cdot 1$ & $99 / 1 V$ & $r / 91$ & 1 & $r / 91$ & سازماندهى & \\
\hline$\cdot / A 1$ & $<\cdot / \cdot \cdot 1$ & $1 r \cdot / 9 F$ & $\mu / \cdot \Lambda$ & 1 & $r / \cdot \Lambda$ & نظارت & \\
\hline .190 & $<\cdot / \cdot \cdot 1$ & $\Delta 1 / 91$ & $1 / r$. & 1 & $1 / r$ & رفتار اجتماعى مناسب & \\
\hline.$/ 91$ & $<\cdot / \cdot \cdot 1$ & rAr/aF & $1 . / 4$. & 1 & $1 . / 4$. & رفتار غير اجتماعى & \\
\hline$\cdot / A 1$ & $<\cdot / \cdot \cdot 1$ & $119 / 90$ & $V / r q$ & 1 & V/rq & يرخاشگُى و رفتار تكانشى & مهارتهاى اجتماعى \\
\hline$\cdot / \Delta \Delta$ & $<\cdot / \cdot \cdot 1$ & $\mathrm{rr} / \mathrm{VV}$ & $\Gamma / \Lambda \Delta$ & 1 & r/AD & اطمينان زياد به خود داشتن & \\
\hline$\cdot / \cdot v$ &.$/ 109$ & $r / .99$ & $\cdot /$ IrF & 1 & . /MF & رابطه با همسالان & \\
\hline
\end{tabular}

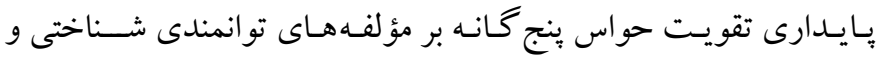
مهارتهـاى اجتماعى دانش آموزان با اختلال ياد گيرى در جدول هـ ارائه شده است.
نتايج تحليل نشـان مىدهد كه تمامى مؤلفههاى تو انمندى شـناختى و مؤلفـهـهـاى مهـارت هـاى اجتمـاعى بـه غير از مؤلفـه رابطـه بـا همســالان (p=•//Dq)

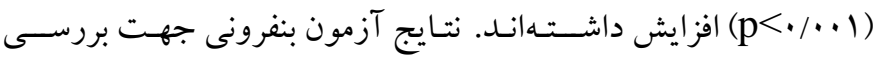

جدول 0: نتايج آزمون بنفرونى جهت بررسى پايدارى تقويت حواس ينج گانه بر مؤلفههاى مهارتهاى اجتماعى و توانمندى شناختى

\begin{tabular}{|c|c|c|c|c|c|c|c|}
\hline معنادارى & ميانتين اصلاح شده & كروهها & خردهمؤلفه & معنادارى & ميانتين اصلاح شده & مرحله & خردهمؤلفه \\
\hline \multirow{2}{*}{.$/ 1 r \Delta$} & $\Delta r / r$ & يس آزمون & رفتار اجتماعى & \multirow{2}{*}{$<\cdot / \cdot \cdot 1$} & 1.194 & يس آزمون & \multirow{2}{*}{ آغاز گرى } \\
\hline & $\$ 9 / 91$ & ييخيرى & مناسب & & $9 / \pi 9$ & ييكيرى & \\
\hline \multirow{2}{*}{.1 .91} & $r / \cdot \Delta$ & يس آزمون & \multirow{2}{*}{ رفتار غير اجتماعى } & \multirow{2}{*}{$\cdot / \cdot 11$} & Ir/A9 & يس آزمون & \multirow{2}{*}{ حافظه فعال } \\
\hline & IN/V & ييخيرى & & & $11 / 11$ & ييخيرى & \\
\hline \multirow{2}{*}{$\cdot / \cdot V^{F}$} & YD/QG & يس آزمون & يرخاشخرى و رفتار & \multirow{2}{*}{$<\cdot / \cdot \cdot 1$} & $19 / 0$ & يس آزمون & \multirow{2}{*}{ برنامهريزى راهبردى } \\
\hline & $1 N / Y 9$ & ييخيرى & تكانشى & & $1 . / 90$ & يِيخيرى & \\
\hline \multirow{2}{*}{$\cdot / Y 91$} & IV/VG & يس آزمون & اطمينان زياد به خود & \multirow{2}{*}{.$/ 190$} & $9 / 94$ & يس آزمون & \multirow{2}{*}{ سازماندهى } \\
\hline & If/VG & بيِيرى & داشتن & & $9 / \pi r$ & ييخيرى & \\
\hline \multirow{2}{*}{.$/ 11 F$} & $r F / T r$ & يس آزمون & \multirow{2}{*}{ رابطه با همسالان } & \multirow{2}{*}{$<\cdot / \cdot \cdot 1$} & $1 \cdot / \Delta r$ & يس آزمون & \multirow{2}{*}{ نظارت } \\
\hline & 19/Dr & ي يخيرى & & & $9 / \pi$ & ييكيرى & \\
\hline
\end{tabular}

مىدهـــ. براى مؤلفههــاى آغاز گرى، برنامهريزى راهبردى، و نظارت در كروه آزمايش ميانگين نمرات تصـسحيح شــده در مرحله يس آزمون در
جـدول ه نـــايـج آزمـون تـعـديـل بـونـفرنى را براى همســنهى خردمؤولفه هاى متغير توانمندى شــناختى و مهارت هاى اجتماعى نشــان 
جـالب توجهى افزايش يـابــ. بـا تقويـت توانمنـدى شــناختى، كودك،

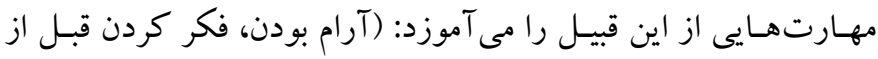

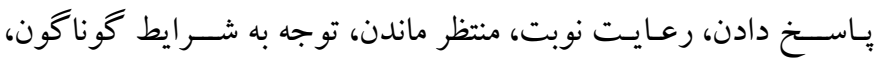

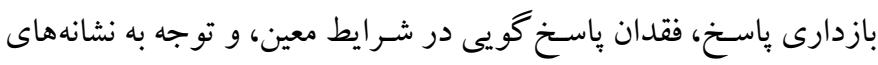

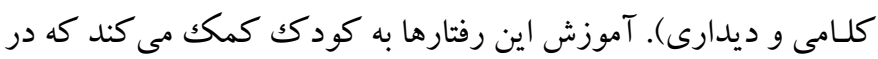

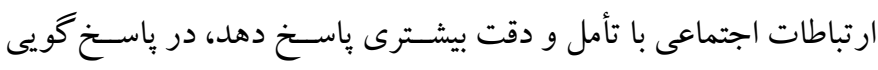

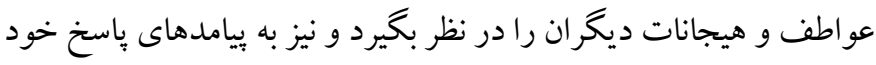

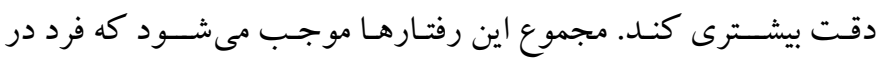

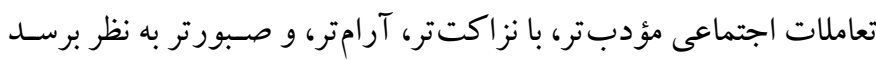
و ديخران نيز مهارتهاى اجتماعى آنها را بهتر ارزيابى كنند.

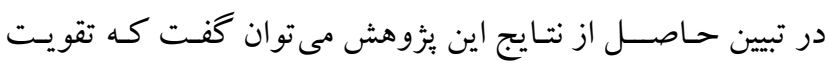

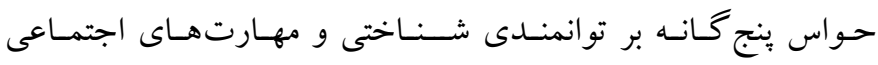

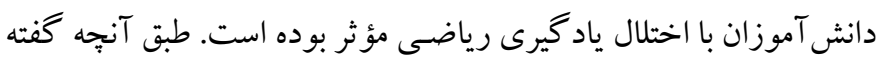

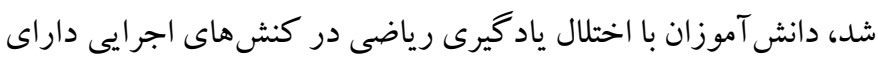

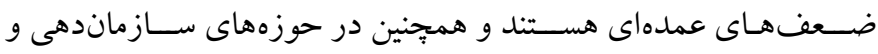

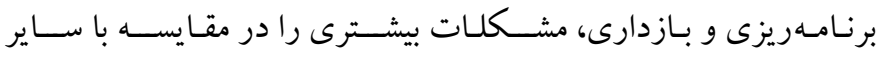

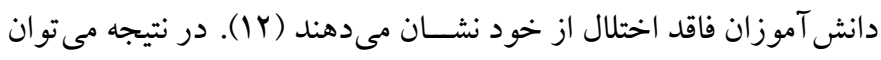

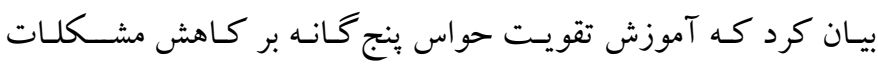

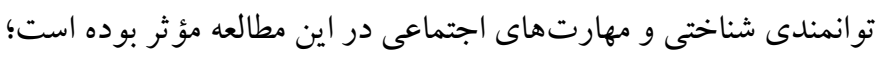

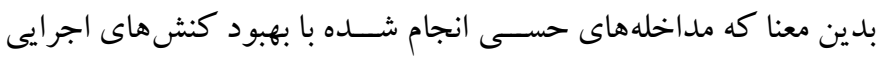

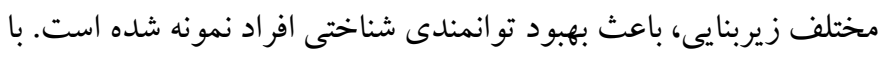
تحريكات ديدارى، شـيدارى، لامسـه، جشايى، و بويايى مى توان به بهبود

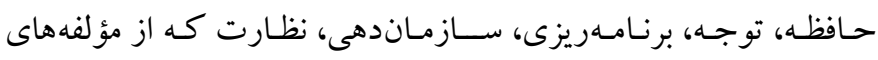

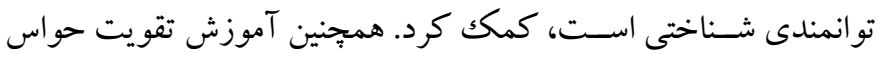

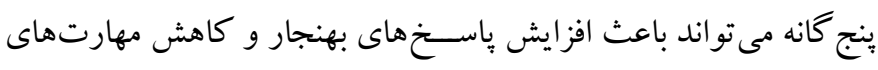

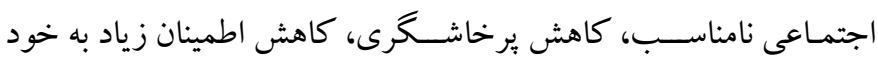

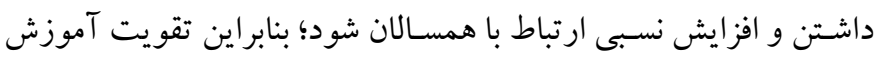

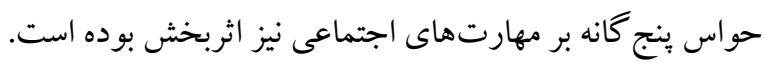

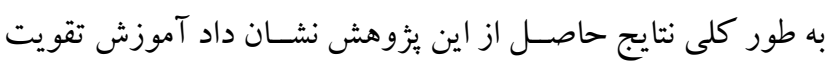

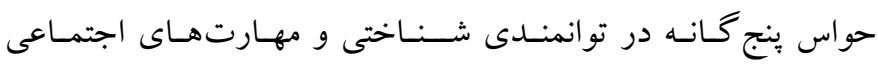

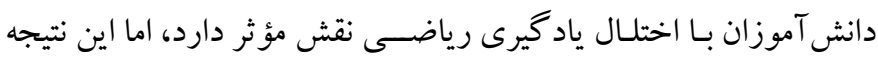
بايد در بافت محدوديتهاى روش شناختى اين مطالعه مورد استتفاده قرار

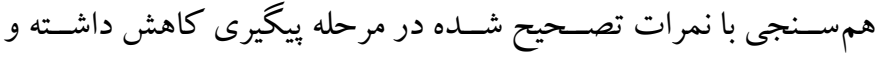

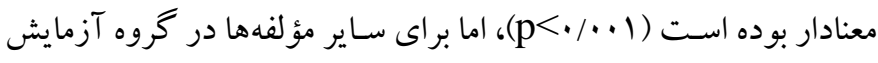
ميانگين نمرات تصحيح شده در مرحله پِ آزمون در هم سنجى با نمرات

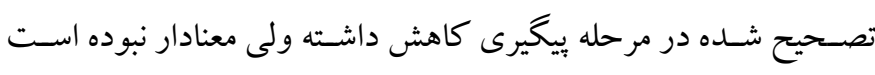

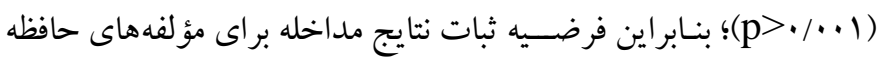

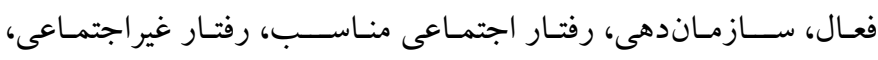

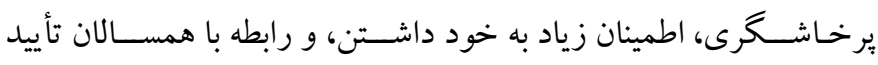

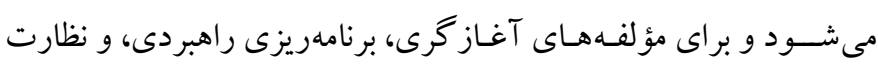
تأييد نمى شود.

\section{بحث و نتيجه كيرى}

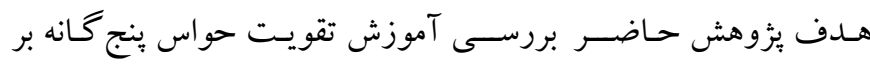

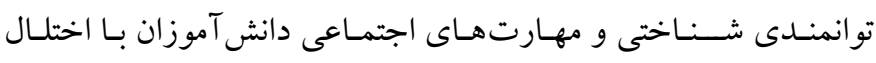

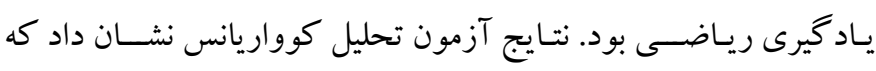

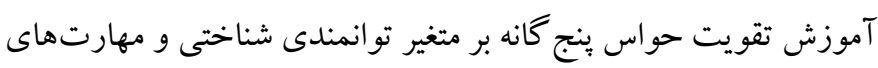

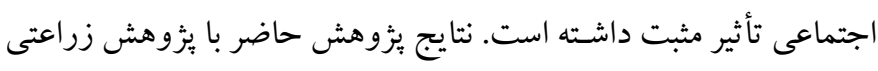

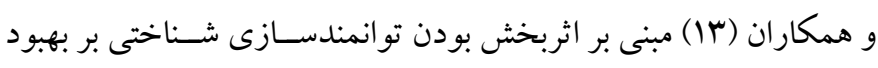

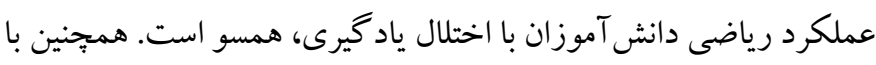

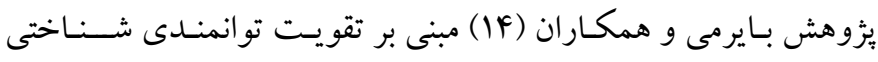

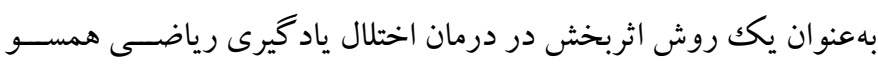

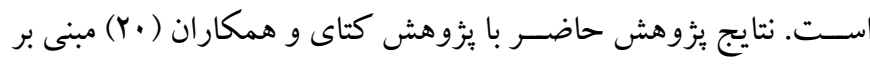

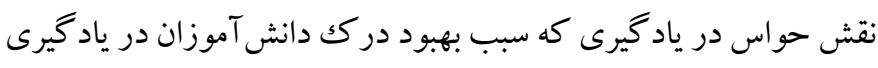

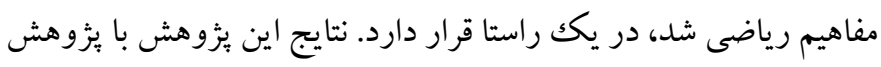

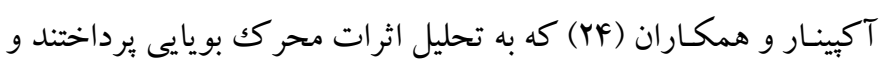

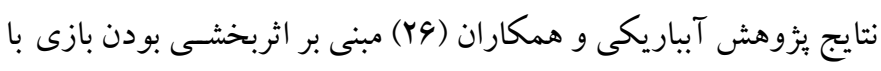

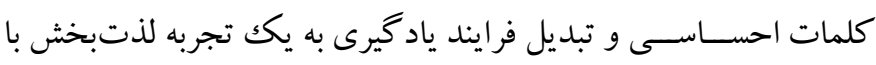

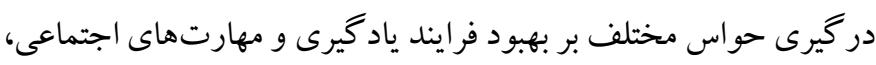
همسويى دارد. يزٔوهش غبارى بناب و همكاران (19) نيز نشان داد كه تقويت حواس

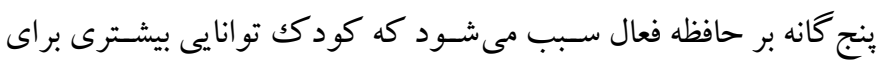

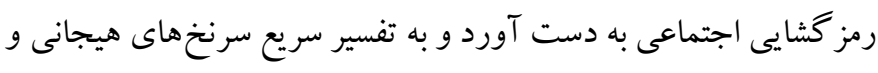

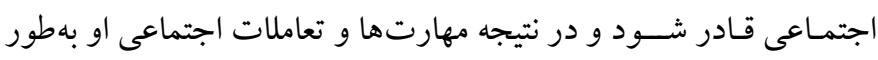


ملاحظات اخلاقى

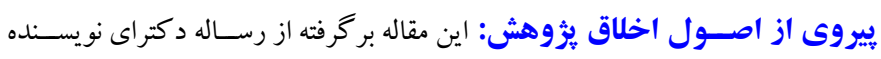

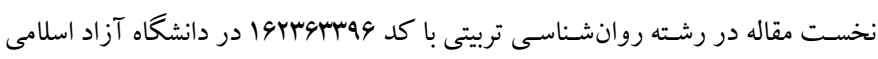

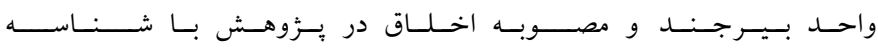
IR.BIRJAND.REC.1399.002 و رضايت كامل افراد نمونه انجام شده است. حامى مالى: اين يُوهش بدون هيج گونه حمايت مالى از سازمان يا نهادى انجام شده اندان است. نقش هر يك از نويسـند كان: اين مقاله بر كرفته از رسـاله دكتراى نويسنده يكم و با راهنمايى و مشاوره ساير نويسند كان انجام شده است.

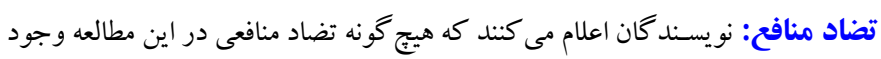
نداشته است. تشكر و قدردانى: از تمامى همكاران و دانش آموزان عزيز و خانو ادههاى محترم آنان

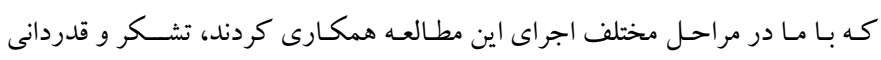
مى كنيم.
كيرد. از محدوديت هاى اين بززوهش منحصسر بودن گروه نمونه يزووهش آنش

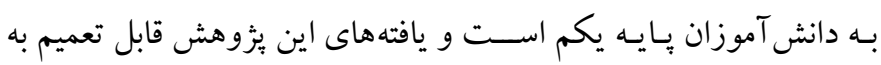

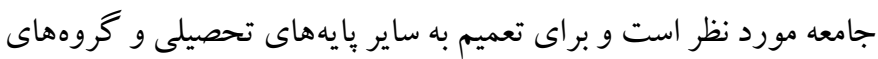

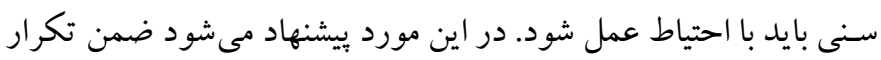

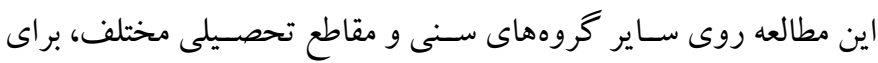

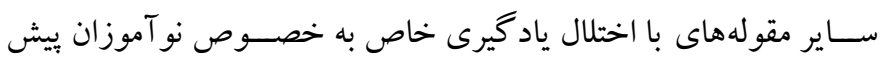

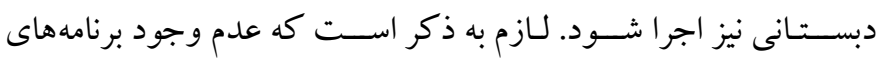

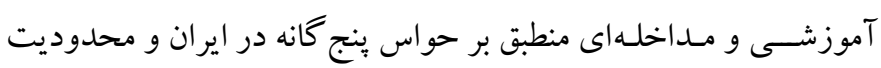

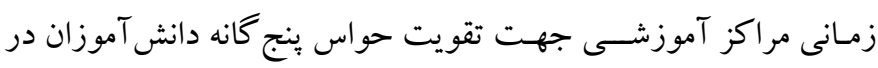

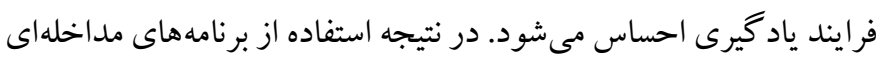

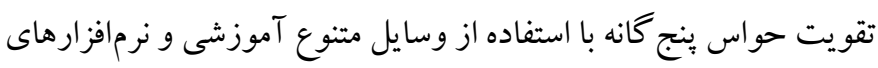

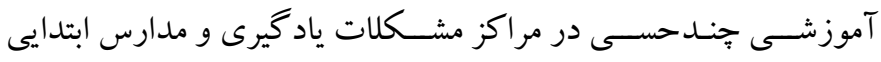

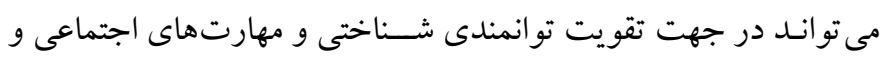
تسهيل ياد گيرى مفاهيم رياضى مفيد باشد. 


\section{References}

1. Karande S, Mahajan V, Kulkarni M. Recollections of learning-disabled adolescents of their schooling experiences: a qualitative study. Indian journal of medical sciences. 2009;63(9). [Link]

2. Swanson LJ. Do the means justify the ends, or do the ends justify the means? Value protection model of justice. Personality and Social Psychology Bulletin. 2014;28(8):452-61.

3. Barzegar Bafrooei K, Mahsa A. The Impact of Playing with Lego on Social Skills of Preschool Children. J Child Ment Health . 2017;(3)4,32-142 . [Link]

4. Kuznetsova A, Brockhoff PB, Christensen RHB. lmerTest: Tests for random and fixed effects for linear mixed effect models (lmer objects of lme4 package). R package version. 2017; 82 (13). [Link]

5. Wallace JC, Kass SJ, Stanny CJ. The cognitive failures questionnaire revisited: dimensions and correlates. The Journal of General Psychology. 2002;129(3):238-56. [Link]

6. Rueda MR, Checa P, Cómbita LM. Enhanced efficiency of the executive attention network after training in preschool children: immediate changes and effects after two months. Developmental Cognitive Neuroscience. 2012;2:S192S204. [Link]

7. Cohen D, Plaza M, Perez-Diaz F, Lanthier O, Chauvin D, Hambourg N, et al. Individual cognitive training of reading disability improves word identification and sentence comprehension in adults with mild mental retardation. Research in Developmental Disabilities. 2006;27(5):50116. [Link]

8. Westerberg H, Klingberg T. Changes in cortical activity after training of working memory - a single-subject analysis. Physiology \& Behavior. 2007;92(1-2):186-92. [Link]

9. Bull R, Espy KA, Wiebe SA. Short-term memory, working memory, and executive functioning in preschoolers: Longitudinal predictors of mathematical achievement at age 7 years. Developmental Neuropsychology. 2008;33(3):20528. [Link]

10. Sharfi K, Rosenblum S. Executive functions, time organization and quality of life among adults with learning disabilities. PloS one. 2016;11(12):e0166939. [Link]

11. Choobdary A, Alizadeh H, Sharifi Daramadi P, Asgari M. Development and Pathology of Executive Functions in Children with Visual Impairment: A Systematic Review Study. J Child Ment Health. 2020; 7 (1) :411-430. [Link]

12. Vahidi S, Manzari Tavakoli A, Manzari Tavakoli H, Soltaninejad A. The Role of Executive Functions in Predicting Math Anxiety in Students with Dyscalculia. MEJDS. 2020; 10 :51-51. [Link]

13. Zeraatee Idehloo R, Zargham Hajebi M, Kamkari K. Comparative study of the effect of the third level of response to intervention and cognitive rehabilitation on math performance of students with dyscalculia. Journal of Learning Disabilities. 2020;9(3):77-106. [Link]
14. Bayrami M NMA, Hashemi T, Movahedi Y. The Effectiveness of Neuropsychological Rehabilitation Treatment on the Continuous Attention Function of Students with Dyscalculia. Community Health Journal. 2016;10(3):45-52. [Link]

15. Hassan AEH. Emotional and behavioral problems of children with learning disabilities. Journal of Educational Policy and Entrepreneurial Research (JEPER). 2015;2(10):66-74. [Link]

16. Toro PA, Weissberg RP, Guare J, Liebenstein NL. A comparison of children with and without learning disabilities on social problem-solving skill, school behavior, and family background. Journal of Learning Disabilities. 1990;23(2):115-20. [Link]

17. Ouherrou N, Elhammoumi O, Benmarrakchi F, El Kafi J. Comparative study on emotions analysis from facial expressions in children with and without learning disabilities in virtual learning environment. Education and Information Technologies. 2019;24(2):1777-92. [Link]

18. Herbert JD, Gaudiano BA, Rheingold AA, Myers VH, Dalrymple K, Nolan EM. Social skills training augments the effectiveness of cognitive behavioral group therapy for social anxiety disorder. Behavior Therapy. 2005;36(2):12538. [Link]

19. Ghobari-Bonab B, Beh-Pajooh A, Afrooz GA, Hakimi Rad E, Arjmandnia AA. The effects of response inhibition and working memory training programs on improving social skills in children with attention deficit / hyperactivity disorder. Quarterly Journal of Psychological Studies. 2014;9 (4): 9-30. [Link]

20. Kátai Z, Juhász K, Adorjáni AK. On the role of senses in education. Computers \& Education. 2008;51(4):1707-17. [Link]

21. Ponticorvo M, Di Fuccio R, Ferrara F, Rega A, Miglino O, editors. Multisensory educational materials: five senses to learn. International Conference in Methodologies and intelligent Systems for Techhnology Enhanced Learning.2018: Springer. [Link]

22. Alkasasbeh AA, Ghinea G, Grønli T-M, editors. The impact of having olfactory media on user performance: Scented vs worded images. 2019 IEEE Conference on e-Learning, eManagement \& e-Services (IC3e).2019: IEEE. [Link]

23. Obaid MAS. The impact of using multi-sensory approach for teaching students with learning disabilities. Journal of International Education Research (JIER). 2013;9(1):75-82. [Link]

24. Akpınara B, Özda F, Yıldırımc B, Batdıd V. The Analysis of the Effects of Olfactive Stimulus in Learning in Context of Educational Technology. Procedia-Social and Behavioral Sciences. 2013;103(0):954-62. [Link]

25. Zhou J, Su Q, Liu P, editors. A Metaphorical Analysis of Five Senses and Emotions in Mandarin Chinese. Workshop on Chinese Lexical Semantics; 2019: Springer. [Link]

26. Shalani B AM, abbariki A. The Effectiveness of Play with feeling Words on Social Skills of Students with Learning 
Disabilities y Research Psychological Applie. 2018;8(4):112. [Link]

27. Afrooz Q, Kamkari K, Shukarzadeh S, A H. Guide to Implementing, Scoring, and Interpreting Children's Wechsler Intelligence Scale for Children (WISC-IV). Tehran: Elme Ostadan Publications. 2012; pp: 1-30. [Link]

28. Sadeghi A, Rabiee M, MR. A. . Validation and Reliability of the Wechsler Intelligence Scale for ChildrenIV. Developmental Psychology: Iranian Psychologists. 2011;7(28):377-86. [Link]

29. Yousefi F, Khayer M. A study on the reliability and the validity of the matson evaluation of social skills with youngstres (MESSY) and sex differences in social skills of high school students in Shiraz, Iran. Journal of Social Sciences and Humanities of Shiraz University. 2002; 18(2): 159-170. [Persian]. [Link]

30. Gioia GA, Isquith PK, Guy SC, L. K. Behavior rating inventory of executive function,Professional manual. Odessa, FL: Psychological Assessment Resources, Incorporated. 2000.

31. Memisevic H, Sinanovic O. Executive functions as predictors of visual-motor integration in children with intellectual disability. Perceptual and motor skills. 2013;117(3):913-22. [Link]

32. MEMISHEVIKJ H. Self-regulation in children with intellectual disability. Journal of Special Education and Rehabilitation. 2015;16.(4-3).71-83. [Link]
33. Abdolmohamadi k, Alizadeh H, Abadi Farhad GS, Taiebli M, fathi a. Psychometric Properties of Behavioral Rating Scale of Executive Functions (BRIEF) in Children aged 6 to 12 Years. Quarterly of Educational Measurement. 2018;8(30):135-51. [Link]

34. Entezari S, Taher M, H A. The Comparison of the Effectiveness of Cognitive Behavioral Therapy and Metacognitive Therapy on Depression, Suicide Ideation, and Masochistic Aggression in Individuals with Subclinical Symptoms of Body Dysmorphic Disorder. J Child Ment Health. 2021;7(4):1-18. [Link]

35. Nodei K, Sarami G, Keramati H. The relation between function and working memory capacity and Students' reading. Journal of Cognitive Psychology. 2016;4(3):11-20 . [Link]

36. Ayres AJ, Tickle LS. Hyper-responsivity to touch and vestibular stimuli as a predictor of positive response to sensory integration procedures by autistic children. American Journal of Occupational Therapy. 1980;34(6):375-81.[Link]

37. Fernald GM. Remedial techniques in basic school subjects. McGraw-Hill; 1943. [Link]

38. Laird J. Abundances in field dwarf stars. II-Carbon and nitrogen abundances. The Astrophysical Journal. 1985;289:556-69. [Link] 